https://doi.org/10.5194/gmd-2021-134

Preprint. Discussion started: 27 August 2021

(c) Author(s) 2021. CC BY 4.0 License. (2) (1)

\title{
A Regional multi-Air Pollutant Assimilation System (RAPAS v1.0) for emission estimates: system development and application
}

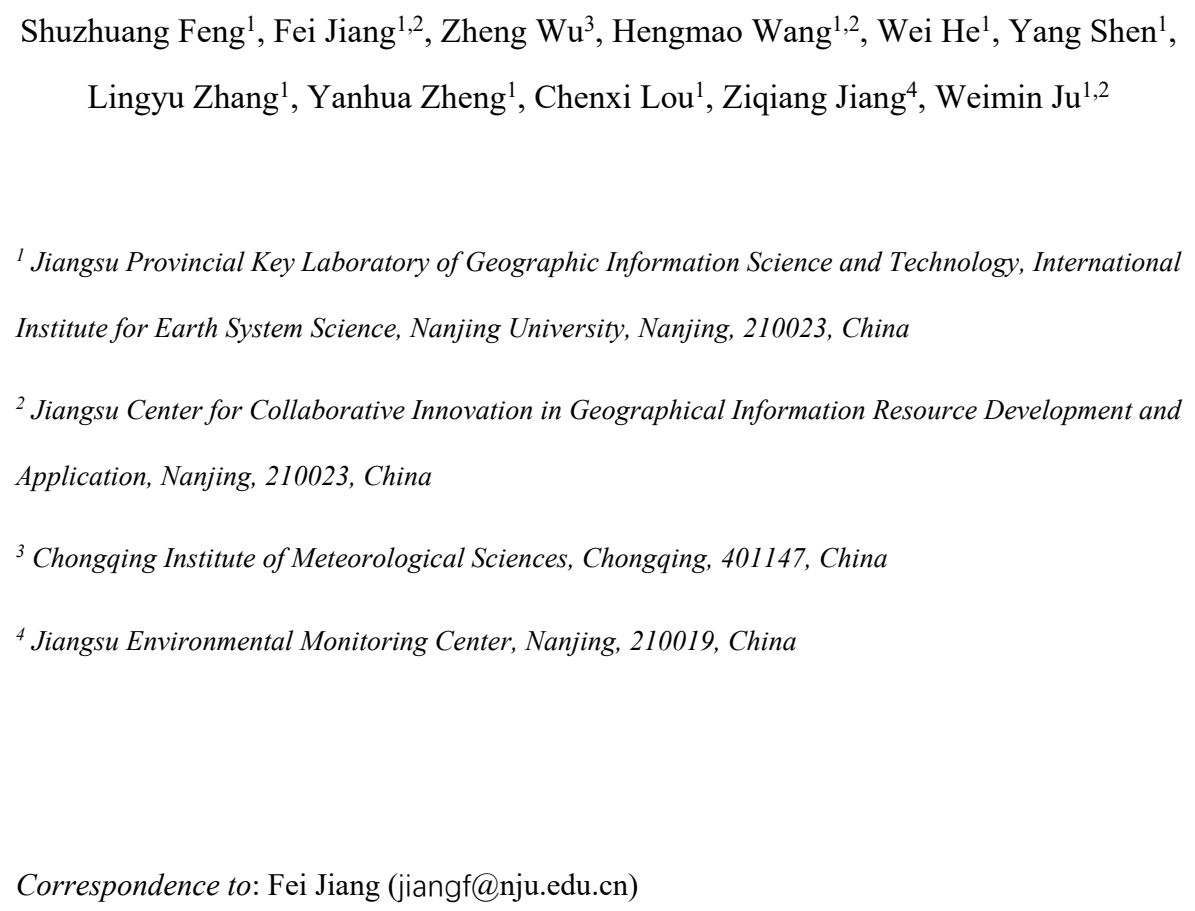



Top-down atmospheric inversion infers surface-atmosphere fluxes from spatially distributed observations of atmospheric compositions, which is a vital means for quantifying large-scale anthropogenic and natural emissions. In this study, we developed a Regional multi-Air Pollutant Assimilation System (RAPAS v1.0) based on the Weather Research and Forecasting/Community Multiscale Air Quality Modeling System (WRF/CMAQ) model, the three-dimensional variational (3DVAR) algorithm and the ensemble square root filter (EnSRF) algorithm. It is capable to simultaneously assimilate spatially distributed hourly in-situ measurements of $\mathrm{CO}, \mathrm{SO}_{2}, \mathrm{NO}_{2}, \mathrm{PM}_{2.5}$ and $\mathrm{PM}_{10}$ concentrations to quantitatively optimize gridded emissions of $\mathrm{CO}, \mathrm{SO}_{2}, \mathrm{NO}_{x}$, primary $\mathrm{PM}_{2.5}\left(\mathrm{PPM}_{2.5}\right)$ and coarse $\mathrm{PM}_{10}(\mathrm{PMC})$ on regional scale. RAPAS includes two subsystems, initial field assimilation (IA) subsystem and emission inversion (EI) subsystem, which are used to generate a "perfect" chemical initial condition (IC), and conduct inversions of anthropogenic emissions, respectively. A "two-step" inversion scheme is adopted in the EI subsystem in its each data assimilation (DA) window, in which the emission is inferred in the first step, and then, it is input into the CMAQ model to simulate the initial field of the next window, meanwhile, it is also transferred to the next window as the prior emission. The chemical IC is optimized through the IA subsystem, and the original emission inventory is only used in the first DA window. Besides, a "super-observation" approach is implemented based on optimal estimation theory to decrease the computational costs and observation error correlations and reduce the influence of representativeness errors. With this system, we estimated the emissions of $\mathrm{CO}, \mathrm{SO}_{2}, \mathrm{NO}_{x}, \mathrm{PPM}_{2.5}$ and $\mathrm{PMC}$ in December 2016 over China using the corresponding nationwide surface observations. The 2016 Multi-resolution Emission Inventory for China (MEIC 2016) was used as the prior emission. The system was run from 26 November to 31 December, in which the IA subsystem was run in the first 5 days, and the EI subsystem was run in the following days. The optimized ICs at the first 5 days and the posterior emissions in December were evaluated against the assimilated and independent observations. Results showed 
that the root mean squared error (RMSE) decreased by $50.0-73.2 \%$, and the correlation coefficient (CORR) increased to $0.78-0.92$ for the five species compared to the simulations without 3DVAR. Additionally, the RMSE decreased by 40.1-56.3\%, and the CORR increased to $0.69-0.87$ compared to the simulations without optimized emissions. For the whole mainland China, the uncertainties were reduced by $44.4 \%$, $45.0 \%, 34.3 \%, 51.8 \%$ and $56.1 \%$ for $\mathrm{CO}, \mathrm{SO}_{2}, \mathrm{NO}_{x}, \mathrm{PPM}_{2.5}$ and $\mathrm{PMC}$, respectively. Overall, compared to the prior emission (MEIC 2016), the posterior emissions increased by $129 \%, 20 \%, 5 \%$, and $95 \%$ for $\mathrm{CO}, \mathrm{SO}_{2}, \mathrm{NO}_{x}$ and $\mathrm{PPM}_{2.5}$, respectively, indicating that there was significant underestimation in the MEIC inventory. The posterior PMC emissions, including anthropogenic and natural dust contributions, increased by $1045 \%$. A series of sensitivity tests were conducted with different inversion processes, prior emissions, prior uncertainties, and observation errors. Results showed that the "two-step" scheme clearly outperformed the simultaneous assimilation of ICs and emissions ("one-step" scheme), and the system is rather robust in estimating the emissions using the nationwide surface observations over China. Our study offers a useful tool for accurately quantifying multi-species anthropogenic emissions at large scales and near-real time.

\section{.} 7

\section{.}

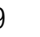
${ }^{12}$ 


\section{Introduction}

Due to rapid economic developments and pollution control legislations, an increasing demand to provide updated emission estimates has arisen, especially in areas where anthropogenic emissions are intensive. Accurately estimating source emission quantities and spatiotemporal changes resulting from various regulations is imperative and valuable for understanding air quality responses and crucial for providing timely instructions for the design of future emissions regulations. However, most inventories have been developed based on a bottom-up approach and are usually updated with a few years delay due to the complexity of gathering all statistical information on activity levels and sector-specific emission factors (Ding et al., 2015). The large uncertainty associated with the low temporal and spatial resolution of these datasets also greatly limits the assessment of emission changes. Some studies (Bauwens et al., 2020; Shi and Brasseur, 2020) have evaluated emission changes indirectly through concentration measurements, but air pollution changes are not only dominated by emission changes, but also highly affected by meteorological conditions (Shen et al., 2021).

Top-down atmospheric inversion infers surface-atmosphere fluxes from spatially distributed observations of atmospheric compositions. Recent efforts have focused on developing air pollution data assimilation (DA) system to conduct the top-down inversion, which is able to integrate model and multi-source and large amount observational information to constrain emission sources. Two major methods, namely, 4D-variational data assimilation (4DVAR) and ensemble Kalman filter (EnKF), are widely used in those DA systems. For example, Jiang et al. (2017) used 4DVAR algorithm to estimate global CO emission trends from 2000-2015 using MOPITT retrievals. Kurokawa et al. (2009) and Stavrakou et al. (2008) also used 4DVAR technique to estimate $\mathrm{NO}_{x}$ emission changes. However, the drawback of the 4DVAR method is the additional development of adjoint models that are technically difficult and cumbersome for complex chemical transport models. Instead, EnKF uses the flowdependent background error covariance generated by ensemble simulations to map the deviations in concentrations to increments of emissions, which is more flexible and 
easier to implement. Many previous studies have used EnKF techniques to assimilate the single or dual species observations to optmize the corresponding emission species (Chen et al., 2019; Peng et al., 2017; Schwartz et al., 2014; Sekiyama et al., 2010). Multispecies data assimilation has shown the advantage of efficiently reducing the uncertainty in emission inventories and has led to improvements in air quality forecasting (Ma et al., 2019; Miyazaki et al., 2012b), since it would offer additional constraints on emission estimates through the improvements in related atmospheric fields, chemical reactions, and gas-particle transformations (Miyazaki and Eskes, 2013). Barbu et al. (2009) updated sulfur oxide $\left(\mathrm{SO}_{x}\right)$ emissions with $\mathrm{SO}_{2}$ gas and sulfate aerosol observations and showed that forecasts were improved overall but degraded when derived only from $\mathrm{SO}_{2}$ or sulfate observations.

The deviation in chemical initial condition (IC) is one of the important sources of error that affects the accuracy of emission inversion, because atmopheric inversion fully attributes the biases in simulated and observed concentrations to the deviations in emissions (Meirink et al., 2006; Peylin et al., 2005). The biases of concentrations would be compensated through unreasonable adjustment of pollution emissions without the optimization of ICs (Tang et al., 2013). Tang et al. (2011) reported that the simultaneous optimizations of the ICs of $\mathrm{O}_{3}, \mathrm{NO}_{x}$ and volatile organic compounds (VOCs) and the emissions of $\mathrm{NO}_{x}$ and VOCs produced an overall better performance in ozone forecasts than the adjustment in emissions only. Similar method of simultaneously optimizing chemical ICs and emissions were also applied to constraining emissions in many previous studies (Ma et al., 2019; Miyazaki et al., 2012a; Peng et al., 2018). Although a large improvement has been achieved, this method still has great limitations because the contributions from the emissions and the chemical ICs to the model's bias are difficult to distinguish (Jiang et al., 2017). Besides, the simultaneous optimization means that assimilation window is independent with each other, generally, the uncertainties of the emissions cannot be fully corrected in time in a window, resulting in an accumulation of errors in the estimation (Jiang et al., 2021). 
nationwide and real-time hourly surface atmospheric observations. This dataset provides an opportunity to improve emission estimates using DA. In this study, a regional multi- air pollutant assimilation system introducing 3DVAR and EnKF DA techniques is constructed to simultaneously assimilate various surface observations (e.g., $\mathrm{CO}, \mathrm{SO}_{2}, \mathrm{NO}_{2}, \mathrm{O}_{3}, \mathrm{PM}_{2.5}$ and $\mathrm{PM}_{10}$ ). Against the limitations of the simultaneous optimization of emissions and chemical ICs in each DA window (here, named as "onestep" method), a "two-step" approach (Sect. 3) is performed, in which the IC of each DA window is simulated using the posterior emission of the pervious DA window. The capability of RAPAS in reanalysis field generation and emission inversion estimation is evaluated. The robustness of the system is also investigated with different prior inventories, uncertainty settings of the prior emission, and observation errors. This paper is organized as follows: in Sect. 2, we introduce the DA system and the observation data, and in Sect. 3, we describe the experimental design. The results of the system performance and sensitivity runs are presented and discussed in Sect. 4, followed by the conclusions in Sect. 5 .

\section{Method and data}

\subsection{System description}

\subsubsection{Procedure of the assimilation system}

A regional air pollutant assimilation system has been preliminarily constructed and successfully applied in our previous studies to optimize gridded $\mathrm{CO}$ and $\mathrm{NO}_{x}$ emissions (Feng et al., 2020a; Feng et al., 2020b). Herein, the system is further extended to simultaneously assimilate multiple species (e.g., $\mathrm{CO}, \mathrm{SO}_{2}, \mathrm{NO}_{2}, \mathrm{O}_{3}, \mathrm{PM}_{2.5}$ and $\mathrm{PM}_{10}$ ) and officially named as the Regional multi- Air Pollutant Assimilation System (RAPASv1.0). The RAPAS mainly includes three components: a regional chemical transport model (CTM), which is coupled offline and used to simulate the meteorological fields and atmospheric compositions, and the 3DVAR and ensemble square root filter (EnSRF) modules, which are used to optimize chemical ICs (Feng et al., 2018; Jiang et al., 2013) and anthropogenic emissions (Feng et al., 2020a; Feng et 
al., 2020b), respectively.

Based on above three components, the RAPAS is divided into two subsystems, namely the IC assimilation (IA) subsystem (CTM plus 3DVAR) and the emission inversion (EI) subsystem (CTM plus EnSRF). As shown in Fig. 1, the IA subsystem is run separately to optimize chemical ICs using the CTM model and cycling assimilation within the 3DVAR framework (Kleist et al., 2009; Wu et al., 2002). It runs only once and provides a "perfect" chemical ICs for the subsequent EI subsystem. The EI subsystem runs cyclically, and in each cycle (DA window), we use a "two-step" calculation scheme. In the first step, the prior emissions $\left(\boldsymbol{X}^{\boldsymbol{b}}\right)$ are perturbed and put into the CTM model to simulate chemical concentration ensembles, which are then sampled according to the locations and times of the observations. The sampled data together with observations and prior emission ensembles are entered into the EnSRF algorithm to generate the optimized emissions $\left(\boldsymbol{X}^{\boldsymbol{a}}\right)$. In the second step, the optimized emissions are entered again into the CTM model to generate the initial fields of the next DA window. Meanwhile, the optimized emissions are transferred to the next window as the prior emissions, which means that the original emission inventory is only used in the first DA window in the EI subsystem. Different from the synchronously scheme ("one-step" scheme), which only runs the model once and optimizes the ICs of the next window and emission at the same time, this "two-step" scheme needs to run the simulations twice, which is time consuming, but it could transfer the errors in the inverted emissions of current DA

191 window to the next one for further correction. The benefit of this scheme will be further presented in Sect. 4.3. 


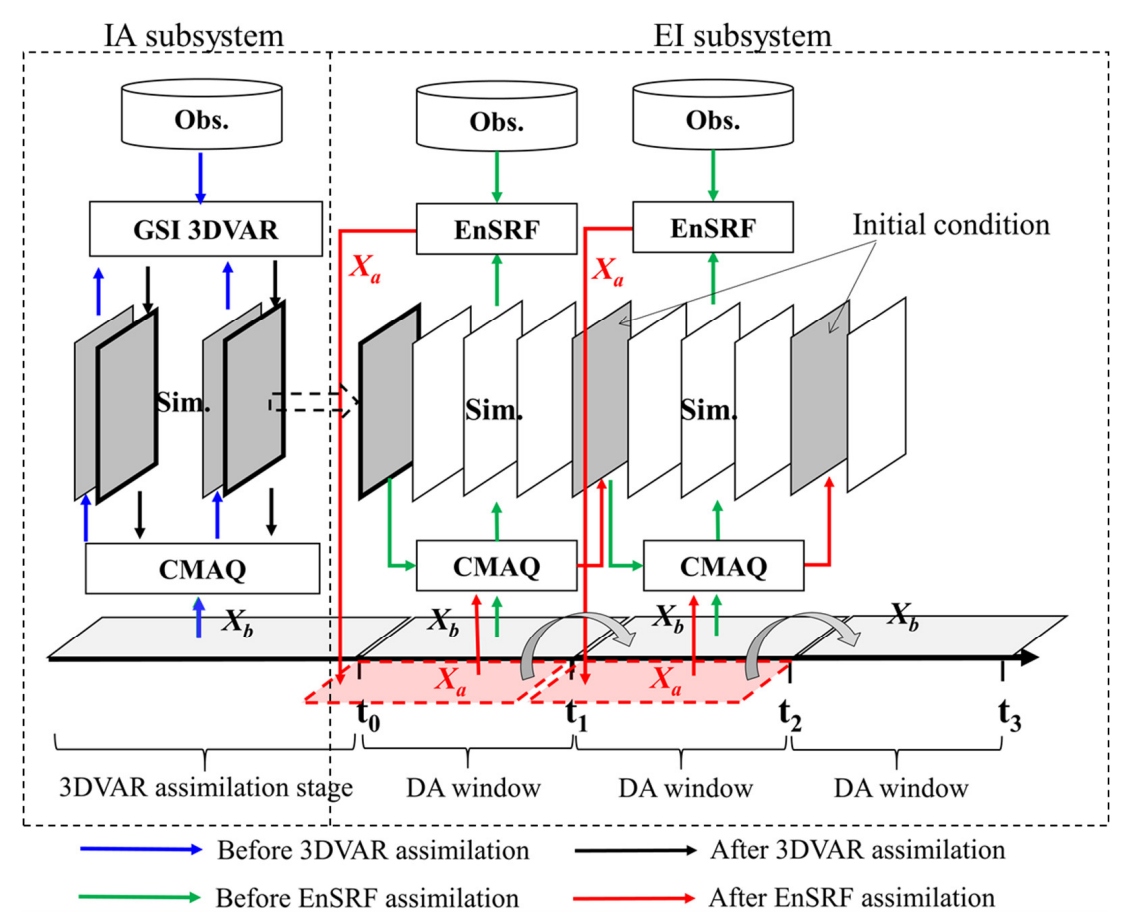

Figure 1. The composition and flow chart of RAPAS.

\subsubsection{Atmospheric transport model}

The regional chemical transport model of WRF/CMAQ is adopted in this study. CMAQ is a regional 3-D Eulerian atmospheric chemistry and transport model with a "oneatmosphere" design developed in the US Environmental Protection Agency (EPA). It could address the complex interactions among multiple pollutants/air quality issues simultaneously. CMAQ is driven by the WRF model, which is a state of the art mesoscale numerical weather prediction system designed for both atmospheric research and meteorological field forecasting. In this study, WRF version 4.0 and CMAQ version 5.0.2 are adopted. The WRF simulations are performed with a $36-\mathrm{km}$ horizontal resolution on $169 \times 129$ grids, and it covers the whole mainland of China (Fig. 2). In the vertical direction, there are 51 sigma levels on sigma-pressure coordinates extending from the surface to $100 \mathrm{hPa}$. The underlying surface of urban and built-up land is replaced by the MODIS land cover retrieval of 2016 to adapt to the rapid 
expansion of urbanization. The CMAQ model is run with the same domain but with three grid cells removed from each side of the WRF domain. There are 15 layers in the CMAQ vertical coordinate, which are compressed from the 51 WRF layers. The meteorological initial and lateral boundary conditions are both provided by the Final (FNL) Operational Global Analysis data of the National Center for Environmental Prediction (NCEP) with a $1^{\circ} \times 1^{\circ}$ resolution at 6 -h intervals. The chemical lateral boundary conditions and chemical ICs in the IA subsystem come from the background profiles. As mentioned above, in the EI subsystem, the chemical IC in the first window is provided by the IA subsystem, and in the following windows, it is forward simulated using optimized emission of previous window. The Carbon Bond 05 with updated toluene chemistry (CB05tucl) and the 6th generation aerosol module (AERO6) are chosen as the gas-phase and aerosol chemical mechanisms, respectively (Appel et al., Table 1. 


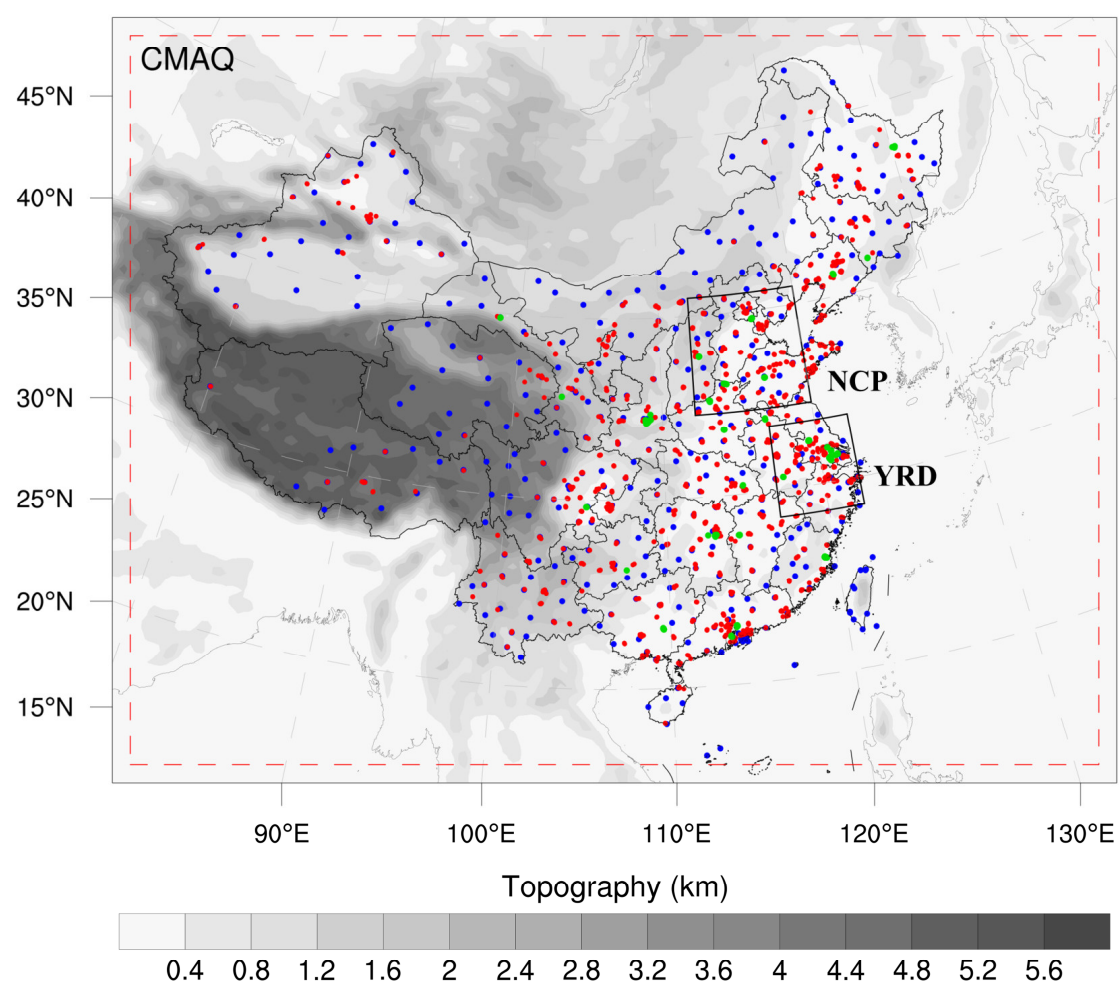

Figure 2. Model domain and observation network. The red dashed frame depicts the CMAQ computational domain; the blue dots represent the meteorological measurement sites; and the red and green dots represent the measurement sites. Observations of all sites are assimilated in the 3DVAR subsystem, while observations of city sites where red dots are averaged are used for assimilation and where green dots are averaged are used for independent evaluation in EI subsystem; the boxed subregions are the North China Plain (NCP) and Yangtze River Delta (YRD); and the shaded area depicts the topography. 
235 Table 1. Configuration options of WRF/CMAQ

\begin{tabular}{ll|ll}
\hline WRF & & CMAQ & \\
\hline Parameter & Scheme & Parameter & Scheme \\
\hline Microphysics & WSM6 & Horizontal/Vertical advection & yamo/wrf \\
Longwave & RRTM & Horizontal/Vertical diffusion & multiscale/acm2 \\
Shortwave & Goddard & Deposition & m3dry \\
Boundary layer & ACM & Chemistry solver & EBI \\
Cumulus & Kain-Fritsch & Photolysis & phot_inline \\
Land-surface & Noah & Aerosol module & AERO6 \\
Surface layer & Revised & Cloud module & cloud_acm_ae6 \\
Urban canopy & No & Gas-phase chemistry & CB05tucl \\
\hline
\end{tabular}

\subsubsection{DVAR assimilation algorithm}

237 The Grid-point Statistical Interpolation (GSI) developed in the US National Centers for

238 Environmental Prediction (NCEP) is employed in this study. Building upon the work

239 of Liu et al. (2011), Jiang et al. (2013) and Feng et al. (2018), we extended it to

240 simultaneously assimilate multiple species (including $\mathrm{CO}, \mathrm{SO}_{2}, \mathrm{NO}_{2}, \mathrm{O}_{3}, \mathrm{PM}_{2.5}$, and

$\left.241 \mathrm{PM}_{10}\right)$ and first used individual aerosol species of $\mathrm{PM}_{2.5}$ as analysis variables within the

242 GSI/WRF/CMAQ framework. Additional works include the construction of surface air

243 pollutant observation operators, the updating of observation errors, and the statistics of

244 background error covariance for the analysis variables. Moreover, the data interface is

245 also modified to read/write the CMAQ output/input file directly, which is easy to

246 implement.

247 In the sense of a minimum analysis error variance, the 3DVAR algorithm optimizes

248 analysis fields with observations by iterative processes to minimize the cost function

$249(\mathrm{~J}(\mathrm{x}))$ defined below:

$250 \mathrm{~J}(\mathrm{x})=\frac{1}{2}\left(\mathbf{x}_{\mathbf{a}}-\mathbf{x}_{\mathbf{b}}\right)^{T} \mathbf{B}^{-1}\left(\mathbf{x}_{\mathbf{a}}-\mathbf{x}_{\mathbf{b}}\right)+\frac{1}{2}\left[H\left(\mathbf{x}_{\mathbf{a}}\right)-\mathbf{y}\right]^{T} \mathbf{R}^{-1}\left[H\left(\mathbf{x}_{\mathbf{a}}\right)-\mathbf{y}\right]$, 
251 where $\mathbf{x}_{\mathbf{a}}$ is a vector of the analysis field; $\mathbf{x}_{\boldsymbol{b}}$ denotes the background field; $\mathbf{y}$ is the vector of observations; $\mathbf{B}$ and $\mathbf{R}$ are the background and observation error covariance matrices, respectively, representing the relative contributions to analysis; and $H$ is the observation operator that maps the model variables to the observation space.

The analysis variables are the $3 \mathrm{D}$ mass concentrations of the pollution compositions (e.g., $\mathrm{CO}$ and sulfate) at each grid point. Hourly surface pollution observations within 1 hour window of the analysis are assimilated. To assimilate the surface pollution observations, model-simulated compositions are first diagnosed at the observation locations. For gas pollutions that are directly used as analysis variables, data units need to be converted from $\mathrm{ppm}$ or $\mathrm{ppb}$ to $\mathrm{mg} \mathrm{m}^{-3}$ or $\mu \mathrm{g} \mathrm{m}^{-3}$ to match with observations. The model-simulated $\mathrm{PM}_{2.5}$ and $\mathrm{PM}_{10}$ concentrations at the ground level are diagnosed as follows:

$P M_{2.5}=f_{i} \times P M_{i}+f_{j} \times P M_{j}+f_{k} \times P M_{k}=\mathrm{OC}+\mathrm{EC}+\mathrm{SO}_{4}^{2-}+\mathrm{NO}_{3}^{-}+\mathrm{NH}_{4}^{+}+$

$S E A S+A P_{2.5}$

$P M_{10}=P M_{i}+P M_{j}+P M_{k}=P M_{2.5}+P M C$

where $f_{i}, f_{j}$, and $f_{k}$ are the $\mathrm{PM}_{2.5}$ fractions of the Aitken, accumulation, and coarse modes, respectively. These ratios are recommended as the concentrations of $\mathrm{PM}_{2.5}$ and fine mode aerosols (i.e., Aitken plus accumulation) could differ because the $\mathrm{PM}_{2.5}$ particles include small tails from the coarse mode in the CMAQ model (Binkowski and Roselle, 2003; Jiang et al., 2006). $P M_{i}, P M_{j}$, and $P M_{k}$ represent the mass concentrations of the 3 modes in the CMAQ model. Seven aerosol species of $\mathrm{PM}_{2.5}$, including organic carbon (OC), elemental carbon (EC), sulfate $\left(\mathrm{SO}_{4}^{2-}\right)$, nitrate $\left(\mathrm{NO}_{3}^{-}\right)$, ammonium $\left(\mathrm{NH}_{4}^{+}\right)$, sea salt (SEAS), and fine-mode unspeciated aerosols $\left(A P_{2.5}\right)$, and additional coarse $\mathrm{PM}_{10}$ (PMC) are extracted as analysis variables, which are updated by the $\mathrm{PM}_{2.5}$ and PMC observations, respectively. Before the calculation of equation (1) within the GSI, the analysis variables are bilinearly interpolated in the horizontal direction to the observation locations. 
278 The computation of background error covariance (B) is generally costly and difficult

279 when a high-dimensional numerical model is used. For simplification, $\mathbf{B}$ is represented as a product of spatial correlation matrices and standard deviations (SDs):

$$
\mathrm{C}=C_{x} \otimes C_{y} \otimes C_{z}
$$

where $\mathbf{D}$ is the background error SD matrix, $\mathbf{C}$ is the background error correlation matrix, $\otimes$ denotes the Kronecker product, and $\boldsymbol{C}_{\boldsymbol{x}}, \boldsymbol{C}_{\boldsymbol{y}}$, and $\boldsymbol{C}_{\boldsymbol{z}}$ denote three onedimensional correlation submatrices in the longitude, latitude, and vertical coordinate directions, respectively. $\boldsymbol{C}_{\boldsymbol{x}}$ and $\boldsymbol{C}_{\boldsymbol{y}}$ are assumed to be isotropic horizontally such that can be represented using a Gaussian function. The correlation between any two points $x_{i}$ and $x_{j}$ in the horizontal can be expressed as follows:

$$
\mathrm{c}\left(x_{i}, x_{j}\right)=e^{-\frac{\left(x_{i}-x_{j}\right)^{2}}{2 L^{2}}}
$$

where $L$ is the horizontal correlation scale, which is estimated using the proxy of the background error (Fig. 3). The vertical correlation matric $\boldsymbol{C}_{\boldsymbol{z}}$ is directly estimated from the model background field since $\boldsymbol{C}_{\boldsymbol{z}}$ is only an $n_{z} \times n_{z}$ (here, $n_{z}=15$ ) matrix. 

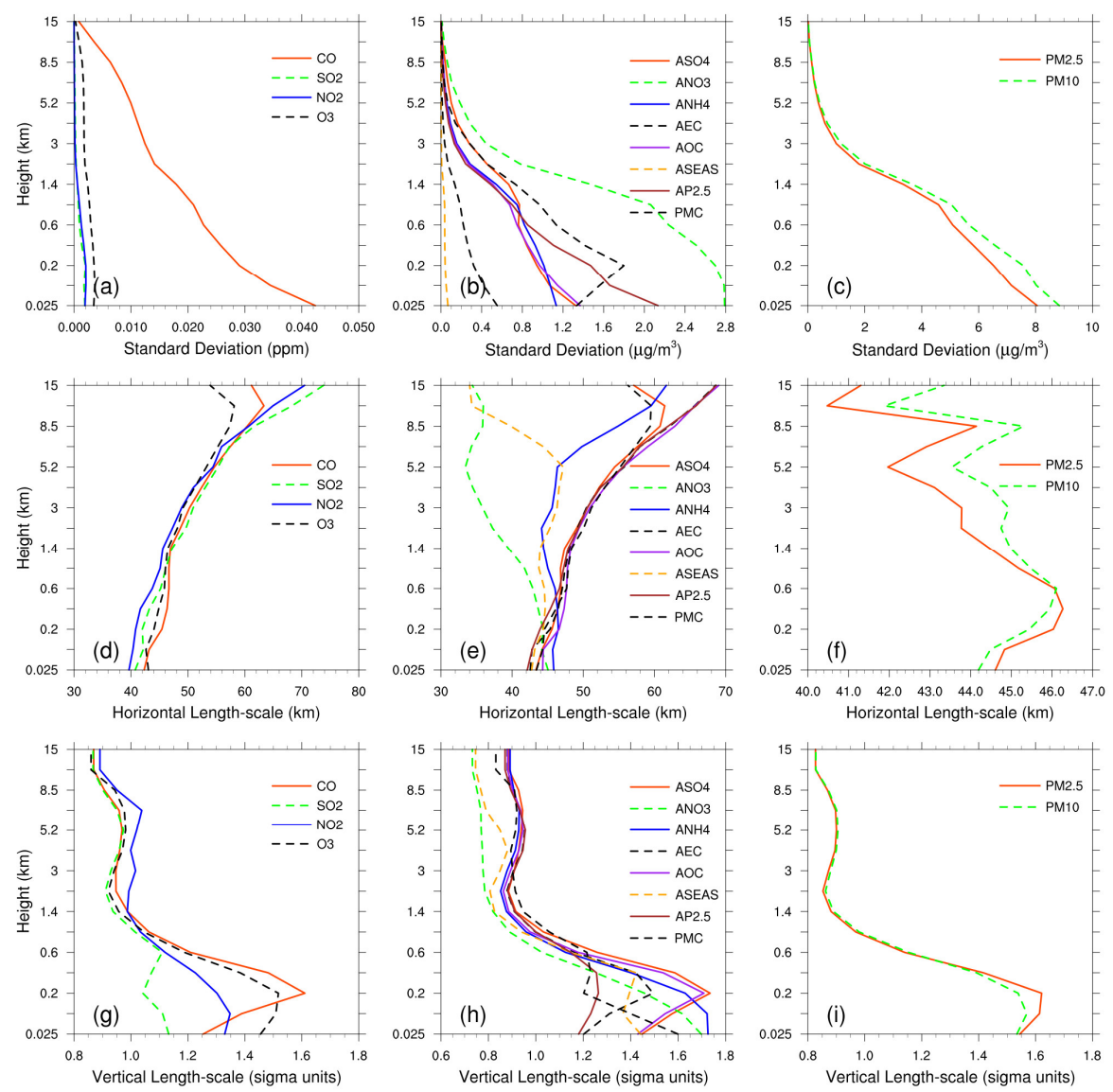

Figure 3. Vertical profiles of standard deviations (top, $\mu \mathrm{g} \mathrm{m}^{-3}$ ), horizontal length scale (middle, $\mathrm{km}$ ) and vertical length scale (bottom, $\mathrm{km}$ ) for $\mathrm{CO}, \mathrm{SO}_{2}, \mathrm{NO}_{2}, \mathrm{O}_{3}$, sulfate, nitrate, ammonium, EC, OC, sea salt, unspeciated aerosols (AP2.5), $\mathrm{PMC}, \mathrm{PM}_{2.5}$ and $\mathrm{PM}_{10}$.

To estimate these matrices, the "NMC" method is used here to compute $\mathbf{B}$ for each variable by taking the differences between forecasts of different lengths valid at the same time (Parrish and Derber, 1992; Rabier et al., 1998). Differences between 24- and 12-h WRF/CMAQ forecasts of 60 pairs (two pairs a day) of analysis variables valid at either 0000 or 1200 UTC over November 2016 are used. The horizontal and vertical length scales of the correlation matrices are estimated by recursive filters (Purser et al., 2003). The vertical distribution of background error SDs is shown in Fig. 3, which 
varies with height and species. The vertical profile of the background error SDs corresponds to the vertical concentration distribution. This means that higher concentrations tend to have larger background error SDs (e.g., CO and nitrate). These SDs exhibit a common reduction with height, especially at the top of the boundary layer. The horizontal correlation of background error determines the propagation of observation information in this direction, while vertical correlation determines the vertical extension of such increments. For gaseous pollutants and individual aerosol components, excluding nitrate and sea salt, the horizontal length scales decrease with increasing heights, while the total particulate matter increases slightly under the boundary layer and then decreases slightly over the boundary layer. The ground-level scale generally spread $40-45 \mathrm{~km}$ for all control variables on average. The vertical length scale of most species increases with height near the ground where they are emitted (Descombes et al., 2015) and then drops rapidly to the height of the upper stable atmosphere, with a scale of $1.4 \mathrm{~km}$.

\subsubsection{EnKF assimilation algorithm}

In EnKF, the time-dependent uncertainties of the state variables are estimated using a Monte Carlo approach through an ensemble. Uncertainty can be propagated with linear or nonlinear dynamic models (flow-dependent background error covariance) by simply implementing ensemble simulations. The EnSRF algorithm introduced by (Whitaker and Hamill, 2002) is used to constrain pollution emissions in this study. EnSRF is a deterministic EnKF that obviates the need to perturb observations, which has a higher computational efficiency and a better performance (Sun et al., 2009).

The perturbation of prior emissions represents the uncertainty. We implement additive emission adjustment methods, which are calculated using the following function.

$$
\boldsymbol{X}_{\boldsymbol{i}}^{\boldsymbol{b}}=\boldsymbol{X}_{\mathbf{0}}^{\boldsymbol{b}}+\boldsymbol{\delta} \boldsymbol{X}_{\boldsymbol{i}}^{\boldsymbol{b}}, \mathrm{i}=1,2, \ldots, \mathrm{N}
$$

where $\boldsymbol{b}$ represents the background (prior) state, $i$ is the identifier of the perturbed samples, $\mathrm{N}$ is the ensemble size ( 40 in this study), and $\delta \boldsymbol{X}_{\boldsymbol{i}}^{\boldsymbol{b}}$ represents the randomly perturbed samples that are added to the prior emissions $\boldsymbol{X}_{\mathbf{0}}^{\boldsymbol{b}}$ to produce ensemble 
samples of the inputs $\boldsymbol{X}_{\boldsymbol{i}}^{\boldsymbol{b}}$. $\delta \boldsymbol{X}_{\boldsymbol{i}}^{\boldsymbol{b}}$ is drawn from Gaussian distributions with a mean of zero and the standard deviation of the prior emission uncertainty in each grid. The state variables of the emissions include $\mathrm{CO}, \mathrm{SO}_{2}, \mathrm{NO}_{x}$, primary $\mathrm{PM}_{2.5}\left(\mathrm{PPM}_{2.5}\right)$ and $\mathrm{PMC}$. We used variable localization to update the analysis, which means that the covariance among different state variables is set to zero (Miyazaki et al., 2012b).

After obtaining an ensemble of state vectors (prior emissions), ensemble runs of the CMAQ model are conducted to propagate these errors in the model with each ensemble sample of state vectors. Combined with observational vector $\boldsymbol{y}$, the state vector is updated by minimizing the analysis variance:

$$
\begin{gathered}
\overline{\boldsymbol{X}^{\boldsymbol{a}}}=\overline{\boldsymbol{X}^{\boldsymbol{b}}}+\mathbf{K}\left(\mathbf{y}-\boldsymbol{H} \overline{\boldsymbol{X}^{\boldsymbol{b}}}\right) \\
\mathbf{K}=\boldsymbol{P}^{\boldsymbol{b}} \boldsymbol{H}^{T}\left(\boldsymbol{H} \boldsymbol{P}^{\boldsymbol{b}} \boldsymbol{H}^{T}+\boldsymbol{R}\right)^{-1} \\
\boldsymbol{P}^{\boldsymbol{b}}=\frac{1}{N-1} \sum_{i=1}^{N}\left(\boldsymbol{X}_{i}^{\boldsymbol{b}}-\overline{\boldsymbol{X}}^{\boldsymbol{b}}\right)\left(\boldsymbol{X}_{i}^{\boldsymbol{b}}-\overline{\boldsymbol{X}}^{\boldsymbol{b}}\right)^{T} \\
\delta \boldsymbol{X}_{\boldsymbol{i}}^{\boldsymbol{a}}=\delta \boldsymbol{X}_{i}^{\boldsymbol{b}}-\widetilde{\boldsymbol{K}} \boldsymbol{H} \delta \boldsymbol{X}_{i}^{\boldsymbol{b}}
\end{gathered}
$$

While employing sequential assimilation and independent observations, $\widetilde{\boldsymbol{K}}$ is calculated as follows:

$$
\widetilde{\boldsymbol{K}}=\left(1+\sqrt{\boldsymbol{R} / \boldsymbol{H} \boldsymbol{P}^{b} \boldsymbol{H}^{T}+\boldsymbol{R}}\right)^{-1} \mathbf{K}
$$

where $\overline{\boldsymbol{X}}^{\boldsymbol{b}}$ represents the mean of the ensemble samples; $\boldsymbol{P}^{\boldsymbol{b}}$ is the ensembleestimated background (a priori) error covariance; $\boldsymbol{P}^{b} \boldsymbol{H}^{T}$ contains the response of the uncertainty in the simulated concentrations to the uncertainty in emissions; $\boldsymbol{K}$ is the Kalman gain matrix of the ensemble mean depending on the $\boldsymbol{P}^{\boldsymbol{b}}$ and observation error covariance $\boldsymbol{R}$, representing the relative contributions to analysis; and $\widetilde{\boldsymbol{K}}$ is the Kalman gain matrix of the ensemble perturbation, which is used to calculate emission perturbations after inversions $\delta \boldsymbol{X}_{i}^{\boldsymbol{a}}$. The ensemble mean $\overline{\boldsymbol{X}^{\boldsymbol{a}}}$ of the analyzed state is taken as the best estimate of the emissions. 
With large volumes of site observations that are recorded at a much higher resolution than the model grid spacing, there would be significant correlated or fully consistent model-data mismatch errors in one cluster, resulting in excessive adjustments and deteriorated model performances (Houtekamer and Mitchell, 2001). To reduce the horizontal observation error correlations and the influence of representativeness errors, a "super-observation" approach combining multiple noisy observations located within the same grid and assimilation window is developed based on optimal estimation theory (Miyazaki et al., 2012a). Previous studies have demonstrated the necessity of datathinning and dealiasing errors (Feng et al., 2020b; Zhang et al., 2009a). The superobservation $y_{\text {new }}$, super-observation error $r_{\text {new }}$ and corresponding simulation $x_{n e w, i}$ of the $i$ th sample are calculated as follows:

$$
\begin{gathered}
1 / r_{\text {new }}^{2}=\sum_{j=1}^{m} 1 / r_{j}^{2} \\
y_{\text {new }}=\sum_{j=1}^{m} w_{j} y_{j} / \sum_{j=1}^{m} w_{j} \\
x_{n e w, i}=\sum_{j=1}^{m} w_{j} x_{i j} / \sum_{j=1}^{m} w_{j}
\end{gathered}
$$

where $j$ is the identifier of $m$ observations within a super-observation grid; $r_{j}$ is the observational error of actual $j$ th observation $y_{j} ; x_{i j}$ represents a simulated concentration using the $i$ th prior emission sample corresponding to the $j$ th observation; and $w_{j}=1 / r_{j}^{2}$ is the weighting factor. The super-observation error decreases as the number of observations used within a super-observation increases. This method has been used in our previous inversions using surface-based (Feng et al., 2020b) and satellite-based (Jiang et al., 2021) observations.

In this study, the DA window is set to 1 day because the model needs a longer time to integrate emission information into the concentration ensembles (Ma et al., 2019). In addition, due to the complexity of hourly emissions, it is very difficult to simulate hourly concentrations that can match the observations well. Although a longer DA 
window could allow more observations to constrain the emission change of one grid, the spurious correlation signals of EnKF would attenuate observation information with time (Bruhwiler et al., 2005; Jiang et al., 2021). Kang et al. (2012) and Zhang et al. (2015) also pointed out that the emission inversion with a long window (e.g., 1 to 3 weeks) is not as accurate as that obtained with a short DA window (e.g., 6 hours to 1 week). Therefore, daily mean simulations and observations are used in the EnSRF algorithm, and daily emissions are optimized in this system.

EnKF is subject to spurious correlations due to the limited number of ensembles when it is applied in high-dimensional atmospheric models, which can cause rank deficiencies in the estimated background error covariance and filter divergence, and further degrade analyses and forecasts (Wang et al., 2020). Covariance localization is performed to reduce spurious correlations caused by the finite ensemble size (Houtekamer and Mitchell, 2001). Covariance localization preserves the meaningful impact of observations on state variables within a certain distance (cutoff radius) but limits the detrimental impact of observations on remote state variables. The localization function of Gaspari and Cohn function (Gaspari and Cohn, 1999) is used in this system, which is a piecewise continuous fifth-order polynomial approximation of a normal distribution. The optimal localization scale is related to the ensemble size, assimilation window, dynamic system, and lifetime of a chemical species in the atmosphere. $\mathrm{CO}$, $\mathrm{SO}_{2}$ and $\mathrm{PM}_{2.5}$ are rather stable in atmosphere, with lifetime more than 1 day. According to the averaged wind speed $(3.3 \mathrm{~m} / \mathrm{s}$, Table 4$)$ and the length of DA window, their localization scales are set to $300 \mathrm{~km}$. In addition, $\mathrm{NO}_{2}$ is rather active, with a lifetime of approximately 10 hours in winter (de Foy et al., 2015), and PMC, which is mainly from local sources, its residence time in the atmosphere is also short due to the rapid deposition rate (Clements et al., 2014; Clements et al., 2016; Hinds, 1982). Their localization scales are set to $150 \mathrm{~km}$ and $250 \mathrm{~km}$, respectively.

\subsection{Prior emissions and uncertainties}

The anthropogenic emissions over China are taken from the 2016 Multi-resolution Emission Inventory for China (MEIC 2016) (Zheng et al., 2018), while those over the 
other regions of East Asia are obtained from the mosaic Asian anthropogenic emission inventory (MIX) (Li et al., 2017). The spatial resolutions of both the MEIC and MIX inventories are $0.25^{\circ} \times 0.25^{\circ}$, and they are both downscaled to match the model grid spacing $(36 \mathrm{~km})$. The spatial distributions of the $\mathrm{CO}, \mathrm{SO}_{2}, \mathrm{NO}_{x}, \mathrm{PPM}_{2.5}$ and $\mathrm{PMC}$ emissions are shown in Fig. 10. The daily emission inventory, which is arithmetic averaged from the combined monthly emission inventory, is directly used in the EI subsystem and employed as the prior emission of the first DA window in the EI subsystem (Fig. 1). MEIC 2012 is used as an alternative a priori over China to investigate the impact of different prior emissions on the optimized emissions. The Model of Emissions of Gases and Aerosols from Nature (MEGAN) (Guenther et al., 2012) is used to calculate time-dependent biogenic emissions. It is also driven by the WRF model in this study. Biomass burning emissions are not included because they have little impact across China during the study period (Zhang et al., 2020).

During the cycling inversions, the inverted emissions of different members converge gradually, and the ensemble-estimated error covariance matrix is very likely to be underestimated. To avoid this, considering the compensation of model errors and comparable emission uncertainties from one day to the next, we impose the same uncertainty on emissions at each DA window. As mentioned above, the optimized emissions of the current DA window are transferred to the next DA window as prior emissions. The technology-based emission inventory developed by Zhang et al. (2009b), basically using the same method as MEIC, shows that the emissions of PMC and PPM 2.5 have the largest uncertainties, followed by $\mathrm{CO}$, and finally $\mathrm{SO}_{2}$ and $\mathrm{NO}_{x}$. Therefore, the uncertainties in this study are set to $40 \%, 40 \%, 30 \%, 25 \%$, and $25 \%$. However, previous studies have shown that the inversely estimated CO and PMC emissions could exceed $100 \%$ higher than the bottom-up emissions (MEIC) in certain areas (Feng et al., 2020b; Ma et al., 2019). According to the extent of underestimation, we set an uncertainty of $100 \%$ for both the CO and PMC emissions at the beginning of the three DA windows to quickly converge the emissions. The mean emission analysis is generally minimally sensitive to the uncertainty setting in our cycle assimilation method (Feng et al., 2020; 
440 Gurney et al., 2004; Miyazaki et al., 2012) because the inversion errors of the current

441 window could be transferred to the next window for further optimization (Sect. 4.3).

\subsection{Observation data and errors}

Hourly averaged surface $\mathrm{CO}, \mathrm{SO}_{2}, \mathrm{NO}_{2}, \mathrm{O}_{3}, \mathrm{PM}_{2.5}$ and $\mathrm{PM}_{10}$ observations from 1504 national control air quality stations are assimilated in this system, which were obtained from the Ministry of Ecology and Environment of the People's Republic of China (http://106.37.208.233:20035/). These sites distribute over most of central and eastern China and become denser near metropolitan areas (see Fig. 2). Value-range and timecontinuity checks are performed to ensure data quality. Value-range checks are mainly performed to eliminate unrealistic or nonspatially representative observations. Only observations within the subjectively selected threshold range are assimilated (Table 2). A time-continuity check is performed to eliminate gross outliers and a sudden anomaly using a function of $|O(t)-O(t \pm 1)| \leq f(t)$, where $O(t)$ and $O(t \pm 1)$ represent observations at time $t$ and $t+1$, respectively, and $f(t)=T_{a}+T_{b} \times O_{t} . T_{b}$ is fixed to 0.15 , and the section of $T_{a}$ is given in Table 2 , which is determined empirically according to the time series change of concentration at each site. It should be noted that, to avoid potential cross-correlations, we assimilated $\mathrm{PM}_{2.5}$ and PMC. Additionally, in the EI subsystem, the observations within each city are averaged to thin the data density and reduce the error correlation (Houtekamer and Mitchell, 2001; Houtekamer and Zhang, 2016). Finally, 336 city sites are available across the mainland of China, in which 311 cities' data are selected for assimilation and the remaining 25 are selected for independent validation (Fig. 2). In the IA subsystem, due to the small horizontal correlation scale (Fig. 3), to obtain more extensive observation constraints, all site observations are assimilated to provide a "perfect" IC for the next emission inversion.

The observation error covariance matrix $(\boldsymbol{R})$ includes both measurement and representation errors. The measurement error $\varepsilon_{0}$ is defined as follow:

$$
\varepsilon_{0}=\text { ermax }+ \text { ermin } \times \Pi_{0}
$$

where ermax is a base error, and $\Pi_{0}$ denotes the observed concentration. These 
parameters for different species are listed in Table 2, which are determined according to Chen et al. (2019), Feng et al., (2018) and Jiang et al. (2013).

The representative error depends on the model resolution and the characteristics of the observation locations, which is calculated using the equations of Elbern et al. (2007) defined as follows:

$$
\varepsilon_{r}=\gamma \varepsilon_{0} \sqrt{\Delta l / L}
$$

where $\gamma$ is a tunable parameter (here, $\gamma=0.5), \Delta l$ is the grid spacing $(36 \mathrm{~km})$, and $L$ indicates the radius (here, $3 \mathrm{~km}$ for simplification) of influence area of an observation. The total observation error $(r)$ is defined as follows:

$$
r=\sqrt{\varepsilon_{0}^{2}+\varepsilon_{r}^{2}}
$$

Table 2. Parameters of quality control and measurement error

\begin{tabular}{ccccccc}
\hline Parameter & $\begin{array}{c}\mathrm{CO} \\
\mathrm{mg} \mathrm{m}^{-3}\end{array}$ & $\begin{array}{c}\mathrm{SO}_{2} \\
\mu \mathrm{g} \mathrm{m}^{-3}\end{array}$ & $\begin{array}{c}\mathrm{NO}_{2} \\
\mu \mathrm{g} \mathrm{m}^{-3}\end{array}$ & $\begin{array}{c}\mathrm{O}_{3} \\
\mu \mathrm{g} \mathrm{m}^{-3}\end{array}$ & $\begin{array}{c}\mathrm{PM}_{2.5} \\
\mu \mathrm{g} \mathrm{m}^{-3}\end{array}$ & $\begin{array}{c}\mathrm{PMC}^{-3} \\
\mu \mathrm{g} \mathrm{m}^{-3}\end{array}$ \\
\hline $\begin{array}{c}\text { value-range } \\
\text { time-continuity } \\
\left(T_{a}\right)\end{array}$ & $0.1-12$ & $1-800$ & $1-250$ & $1-250$ & $1-800$ & $1-900$ \\
$\begin{array}{c}\text { ermax } \\
\text { ermin }\end{array}$ & 0.05 & 160 & 70 & 80 & 180 & 180 \\
\hline & $0.5 \%$ & $0.5 \%$ & $0.5 \%$ & $0.5 \%$ & $0.75 \%$ & $0.75 \%$ \\
\hline
\end{tabular}

\section{Experimental design}

RAPAS is conducted according to the procedure and settings described in Sect. 2. The IA subsystem is run from 26 to 31 November 2016 with a 6-hour interval cycling assimilation to optimize ICs (ICDA). A better IC at 0000 UTC on December 1 can be obtained by 5 -day high-frequency cycling assimilation and atmospheric mixing. Then the EI subsystem is run for December 2016 with a 1-day assimilation window to optimize emissions (EMDA). Both assimilation experiments use the combined prior emission inventories of 2016 as described in Sect. 2.2, and the emission base year coincides with the research stage. To evaluate the IC improvements from the IA 
subsystem, an experiment without 3DVAR (ICNO) is conducted with the same meteorological fields and physical and chemistry parameterization settings as those of the ICDA. To evaluate the posterior emissions of the EI subsystem, two parallel forward modeling experiments are performed for December 2016, namely, a control experiment (CEP) with prior (MEIC 2016) emissions and a validation experiment (VEP) with posterior emissions. Both experiments use the same initial field at 0000 UTC on December 01 generated through the IA subsystem. Similar to the above, the only differences between CEP and VEP are emissions. Table 3 gives a summary of these different simulation experiments.

To investigate the robustness of our system, 7 sensitivity tests (from EMS1 to EMS7, see Table 3) are performed. These experiments are all based on EMDA. In EMS1, rather than forward simulated using the optimized emissions of the previous DA window in EMDA, the initial fields of each DA window are optimized using the 3DVAR algorithm directly and the observations at the corresponding moment as mentioned in Sect. 2.3. The objective of this experiment is to investigate the advantages of the "two-step" calculation scheme in the EI subsystem as introduced in Sect. 2.1. EMS2 uses MEIC 2012 as the original prior emission in China, aiming to investigate the impact of different prior inventories on the estimates of emissions. Four other experiments, namely EMS3-6, aim to test the impact of different prior uncertainty settings, in which, the prior uncertainties are reduced by $-50 \%$ and $-25 \%$, and increased by $25 \%$ and $50 \%$, respectively. EMS7 aims to evaluate the impact of observation errors on emission estimates, in which all the observation errors are magnified twice. Seven forward modeling experiments (VEP1, VEP2, ..., VEP7) are also performed with posterior emissions of EMS1 to EMS7 to evaluate their performances, respectively.

(n) 
516 Table 3. Experiments conducted in this study

\begin{tabular}{|c|c|c|c|c|c|c|}
\hline $\begin{array}{l}\text { Exp. } \\
\text { Type }\end{array}$ & $\begin{array}{l}\text { Exp. } \\
\text { Name }\end{array}$ & Period & Initial field & Emission & IA & EI \\
\hline \multirow[b]{2}{*}{ Assimilation } & ICDA & $\begin{array}{l}26-31 \\
\text { November }\end{array}$ & $\begin{array}{l}\text { previous } 6-\mathrm{hr} \\
\text { interval cycling } \\
\text { forecast }\end{array}$ & $\begin{array}{l}\text { MEIC } 2016 \text { for } \\
\text { November }\end{array}$ & YES & NO \\
\hline & EMDA & $\begin{array}{l}1-31 \\
\text { December }\end{array}$ & $\begin{array}{l}0000 \text { UTC on } \\
\text { December } 1 \text {, taken } \\
\text { from ICDA }\end{array}$ & $\begin{array}{l}\text { MEIC } 2016 \text { for } \\
\text { December (the first } \\
\text { DA window), } \\
\text { optimized emissions } \\
\text { of the previous } \\
\text { window (other DA } \\
\text { windows) }\end{array}$ & $\mathrm{NO}$ & YES \\
\hline \multirow{4}{*}{ Sensitivity } & EMS1 & $\begin{array}{l}1-31 \\
\text { December }\end{array}$ & $\begin{array}{l}\text { Forecast with prior } \\
\text { emissions in the } \\
\text { previous window }\end{array}$ & The same as EMDA & YES & YES \\
\hline & EMS2 & $\begin{array}{l}1-31 \\
\text { December }\end{array}$ & $\begin{array}{l}\text { The same as } \\
\text { EMDA }\end{array}$ & $\begin{array}{l}\text { The same as EMDA, } \\
\text { but for EMIC } 2012\end{array}$ & NO & YES \\
\hline & EMS3-6 & $\begin{array}{l}1-31 \\
\text { December }\end{array}$ & $\begin{array}{l}\text { The same as } \\
\text { EMDA }\end{array}$ & $\begin{array}{l}\text { The same as EMDA, } \\
\text { but with a } \pm 25 \% \text { or } \\
\pm 50 \% \text { of default } \\
\text { uncertainty }\end{array}$ & NO & YES \\
\hline & EMS7 & $\begin{array}{l}1-31 \\
\text { December }\end{array}$ & $\begin{array}{l}\text { The same as } \\
\text { EMDA }\end{array}$ & $\begin{array}{l}\text { The same as EMDA, } \\
\text { but with a }+100 \% \text { of } \\
\text { default observation } \\
\text { errors }\end{array}$ & $\mathrm{NO}$ & YES \\
\hline \multirow{4}{*}{ Verification } & ICNO & $\begin{array}{l}26-31 \\
\text { November }\end{array}$ & The same as ICDA & The same as ICDA & $\mathrm{NO}$ & NO \\
\hline & CEP & $\begin{array}{l}1-31 \\
\text { December }\end{array}$ & $\begin{array}{l}\text { The same as } \\
\text { EMDA }\end{array}$ & $\begin{array}{l}\text { MEIC } 2016 \text { for } \\
\text { December }\end{array}$ & $\mathrm{NO}$ & NO \\
\hline & VEP & $\begin{array}{l}1-31 \\
\text { December }\end{array}$ & $\begin{array}{l}\text { The same as } \\
\text { EMDA }\end{array}$ & $\begin{array}{l}\text { Posterior emissions of } \\
\text { EMDA }\end{array}$ & NO & NO \\
\hline & VEP1-7 & $\begin{array}{l}1-31 \\
\text { December }\end{array}$ & $\begin{array}{l}\text { The same as } \\
\text { EMDA }\end{array}$ & $\begin{array}{l}\text { Posterior emissions of } \\
\text { EMS1-7 }\end{array}$ & $\mathrm{NO}$ & NO \\
\hline
\end{tabular}

\section{Results}

\section{$518 \quad 4.1$ Evaluations}

\section{$519 \quad$ 4.1.1 Simulated meteorological fields}

520 In the RAPAS system, the inversion approach attributes all the biases between the 
521 simulated and observed concentrations to the emissions. The meteorological fields

522 dominate the physical and chemical processes of the air pollutants in the atmosphere,

523 and thus their simulation accuracy would significantly affect the estimates of emissions

524 in this study. To quantitatively evaluate the performance of the WRF simulations, the

525 mean bias (BIAS), root mean square error (RMSE), and correlation coefficient (CORR)

526 were calculated against the surface meteorological observations measured at 400

527 stations, which were obtained from the National Climate Data Center (NCDC)

528 integrated surface database (http://www.ncdc.noaa.gov/oa/ncdc.html). The spatial

529 distribution of the meteorological stations (blue dots) is shown in Fig. 2. The simulated

530 temperature at $2 \mathrm{~m}$ (T2), relative humidity at $2 \mathrm{~m}(\mathrm{RH} 2)$, and wind speed at $10 \mathrm{~m}$ (WS10)

531 from 26 November to 31 December 2016 are evaluated against the observations. Table

5324 summarizes the statistical results of the evaluations of the simulated meteorological

533 parameters. Overall, the T2 and RH2 are slightly underestimated, with biases of $-0.1^{\circ} \mathrm{C}$

534 and $-3.8 \%$, respectively. The CORRs are approximately 0.98 for T2 and 0.94 for RH2,

535 showing good consistency between the observations and simulations. The WS10 is

536 overestimated, with a bias of $0.7 \mathrm{~m} / \mathrm{s}$ and an RMSE of $0.8 \mathrm{~m} / \mathrm{s}$, but is better than many

537 other studies (Chen et al., 2016; Jiang et al., 2012a; Jiang et al., 2012b). Therefore,

538 WRF can generally reproduce the meteorological conditions sufficiently in terms of

539 their temporal variation and magnitude over China, which is adequate for our inversion

540 estimation.

541 Table 4. Statistics comparing the simulated and observed 10-m wind speed (WS10,

$542 \mathrm{~m} / \mathrm{s}), 2-\mathrm{m}$ temperature $\left(\mathrm{T} 2,{ }^{\circ} \mathrm{C}\right)$, and 2-m relative humidity $(\mathrm{RH} 2, \%)$ averaged over all 543400 stations.

\begin{tabular}{cccccc}
\hline Variable Met. & Mean Obs. & Mean Sim. & BIAS & RMSE & CORR \\
\hline WS10 (m/s) & 2.6 & 3.3 & 0.7 & 0.8 & 0.72 \\
T2 $\left({ }^{\circ} \mathrm{C}\right)$ & 2.9 & 2.8 & -0.1 & 0.7 & 0.98 \\
RH2 $(\%)$ & 66.3 & 62.6 & -3.8 & 5.2 & 0.94 \\
\hline
\end{tabular}

* BIAS, mean bias; RMSE, root mean square error; CORR, correlation coefficient 


\section{$545 \quad$ 4.1.2 Initial fields}

546 Figure 4 shows the evaluations of the analyzed concentrations of the 6 species against 547 surface observations. For comparison, the evaluations of the simulations without 548 3DVAR (ICNO) are also shown in Fig. 4. The simulations of the ICNO experiment 549 (red dots) are scattered on both sides of a central line, as large systematic biases remain 550 across many measurement sites. Conversely, the ICDA experiment (blue dots) shows 551 much better agreement with observations than those from ICNO. The statistics show 552 that there are large systematic biases in the ICNO simulations, with large RMSEs and 553 small CORRs for all species, especially for CO and PMC. After the assimilation of 554 surface observations, the RMSE of CO decreases to $0.7 \mathrm{mg} \mathrm{m}^{-3}$, and those of $\mathrm{SO}_{2}, \mathrm{NO}_{2}$, $555 \mathrm{O}_{3}, \mathrm{PM}_{2.5}$ and PMC decrease to 22.0, 12.0, 9.6, 20.5 and $19.6 \mu \mathrm{g} \mathrm{m}^{-3}$, respectively, with 556 respective reduction rates of $50.0 \%, 73.1 \%, 61.0 \%, 64.7 \%, 69.5 \%$, and $60.8 \%$ 557 compared to the ones of the ICNO (Table 5). The CORRs of ICDA increase by $290.0 \%$, $558291.3 \%, 55.4 \%, 87.2 \%, 130.0 \%$ and $214.8 \%$ to $0.78,0.90,0.87,0.88,0.92$ and 0.85 , 559 respectively. These statistics indicate that the initial fields can be adjusted effectively 560 by our IA subsystem. 

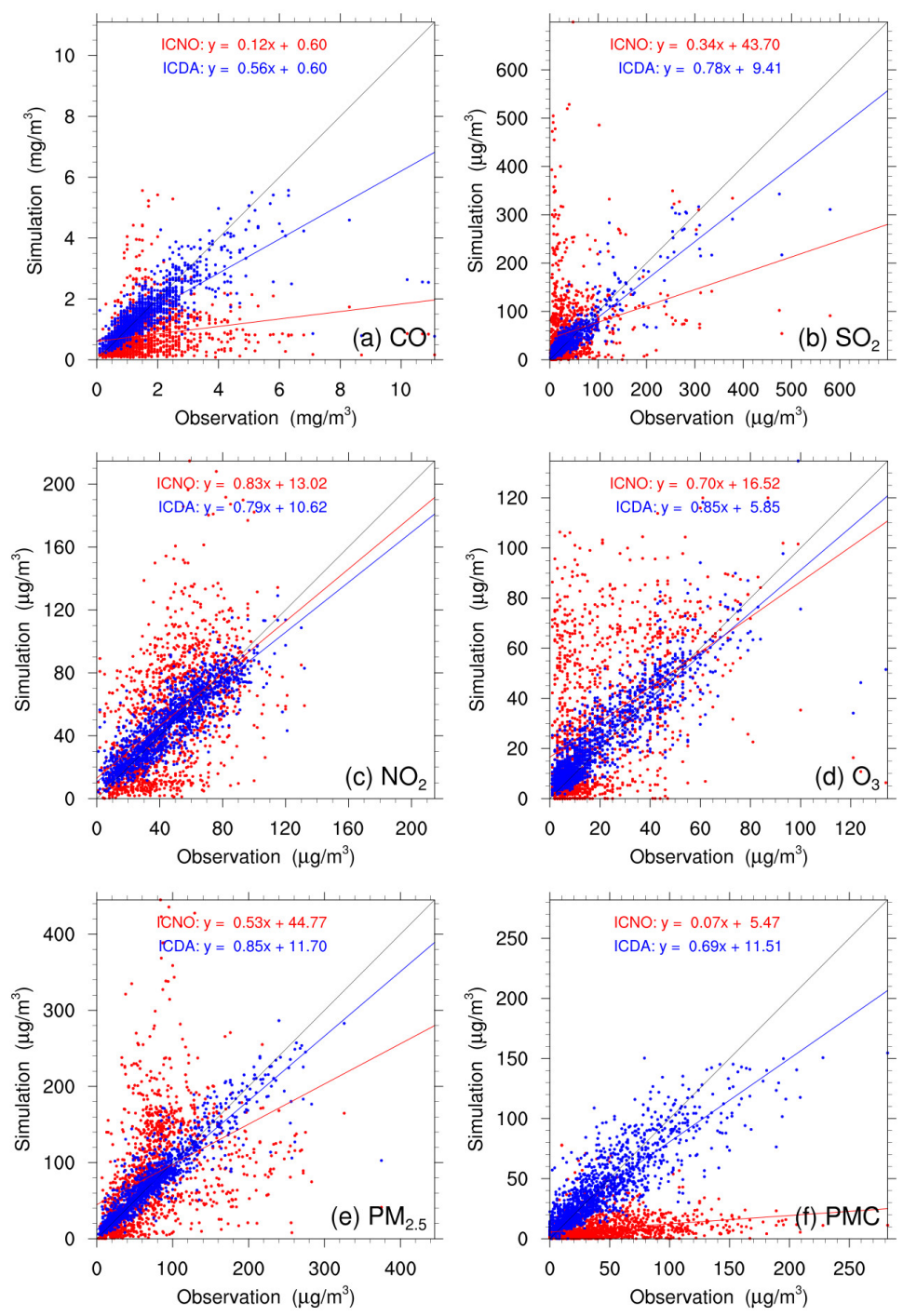

562 Figure 4. Scatter plots of simulated versus observed (a) $\mathrm{CO}$, (b) $\mathrm{SO}_{2}$, (C) $\mathrm{NO}_{2}$, (d) $\mathrm{O}_{3}$,

563 (e) $\mathrm{PM}_{2.5}$ and (f) PMC mass concentrations at 0000 UTC on December 1 initializations

564 from the background (red) and analysis (blue) fields. 
567 Table 5. Comparisons of the surface $\mathrm{CO}, \mathrm{SO}_{2}, \mathrm{NO}_{2}, \mathrm{O}_{3}, \mathrm{PM}_{2.5}$ and $\mathrm{PMC}$ mass 568 concentrations from the control and assimilation experiment against observations 569 aggregated over all analysis times. $\mathrm{CO}$ unit: $\mathrm{mg} \mathrm{m}^{-3}$; others units: $\mu \mathrm{g} \mathrm{m}^{-3}$.

\begin{tabular}{ccccccc}
\hline \multirow{2}{*}{ Species } & Exp. Name & $\begin{array}{c}\text { Mean } \\
\text { Obs. }\end{array}$ & $\begin{array}{c}\text { Mean } \\
\text { Sim. }\end{array}$ & BIAS & RMSE & CORR \\
\hline \multirow{2}{*}{$\mathrm{CO}$} & ICNO & \multirow{2}{*}{1.5} & 0.8 & -0.7 & 1.4 & 0.20 \\
& ICDA & & 1.5 & -0.1 & 0.7 & 0.78 \\
\hline \multirow{2}{*}{$\mathrm{SO}_{2}$} & ICNO & \multirow{2}{*}{36.3} & 56.0 & 19.7 & 81.7 & 0.23 \\
& ICDA & & 37.8 & 1.5 & 22.0 & 0.90 \\
\hline \multirow{2}{*}{$\mathrm{NO}_{2}$} & ICNO & \multirow{2}{*}{45.8} & 51.1 & 5.3 & 30.8 & 0.56 \\
& ICDA & & 47.0 & 1.1 & 12.0 & 0.87 \\
\hline \multirow{2}{*}{$\mathrm{O}_{3}$} & ICNO & \multirow{2}{*}{20.5} & 30.8 & 10.4 & 27.2 & 0.47 \\
& ICDA & & 23.3 & 2.8 & 9.6 & 0.88 \\
\hline \multirow{2}{*}{$\mathrm{PM}_{2.5}$} & ICNO & \multirow{2}{*}{70.9} & 82.2 & 11.3 & 67.3 & 0.40 \\
& ICDA & & 71.8 & 0.9 & 20.5 & 0.92 \\
\hline \multirow{2}{*}{$\mathrm{PMC}^{*}$} & ICNO & \multirow{2}{*}{43.5} & 8.5 & -35.0 & 50.0 & 0.27 \\
\hline
\end{tabular}

570

571

572

573

574

575

576

577

578

579

580

581

582

583

* BIAS, mean bias; RMSE, root mean square error; CORR, correlation coefficient

\subsubsection{Posterior emissions}

Due to mismatched spatial scales, it is difficult to directly evaluate the optimized emissions against observations. Generally, we indirectly validate them by comparing the forward simulated concentrations using the posterior emissions against atmospheric measurements (e.g., Jiang et al. (2014), Jin et al. (2018), and Peters et al. (2007)). Figure 5 shows the spatial distributions of the mean biases between the simulated gaseous pollutants using prior and posterior emissions and assimilated observations. In the CEPs, for each species, the distribution of biases is similar to the increments in background fields constrained through 3DVAR as shown in Fig. S1. For example, almost all sites have large negative biases for $\mathrm{CO}$, while for $\mathrm{SO}_{2}$ and $\mathrm{NO}_{2}$, positive biases are mainly distributed over the North China Plain (NCP), Yangtze River Delta (YRD), Sichuan Basin (SCB) and Central China, and negative biases are over the rest areas. After constraining with observations, the biases of all the 3 gaseous air pollutants are 
significantly reduced in most sites. For $\mathrm{CO}$, the biases at $62 \%$ of the sites decreased to absolute values less than $0.2 \mathrm{mg} \mathrm{m}^{-3}$, and for $\mathrm{SO}_{2}$ and $\mathrm{NO}_{2}$, the biases at $52 \%$ and $47 \%$ of the sites were within $\pm 4 \mu \mathrm{g} \mathrm{m}^{-3}$. However, large negative biases are still observed in part of western Chinas, indicating that the uncertainties of the posterior emissions are still large in western China, which may be attributed to the large biases in prior emissions and to the relatively limited observation. Overall, the statistics show that there are different levels of improvements at $92 \%, 85 \%$ and $85 \%$ of the total 311 assimilation sites for $\mathrm{CO}, \mathrm{SO}_{2}$ and $\mathrm{NO}_{2}$, respectively. The small amount of sites with worse performance may be related to the overadjusted emissions by EI or contradictory adjustments caused by opposite biases in adjacent areas.

Table 6 lists the statistical results of the evaluations averaged over the whole mainland of China. For CO, the mean bias is $-0.8 \mathrm{mg} \mathrm{m}^{-3}$ with the prior emissions, while it substantially reduces to $-0.1 \mathrm{mg} \mathrm{m}^{-3}$ with a reduction rate of $89.6 \%$ when simulating with the posterior emissions. Additionally, the RMSE decreases by $48.1 \%$ from 1.08 to $0.56 \mathrm{mg} \mathrm{m}^{-3}$, and the CORR increases by $76.1 \%$ from 0.46 to 0.81 . For $\mathrm{SO}_{2}$ and $\mathrm{NO}_{2}$, the regional mean biases slightly increase as the positive/negative biases among different sites might be offset. However, the RMSEs decrease to 17.7 and $12.3 \mu \mathrm{g} \mathrm{m}^{-3}$, respectively, which are $58.3 \%$ and $50.8 \%$ lower than those of CEPs, and the CORRs increase by $125.6 \%$ and $35.4 \%$, both reaching up to 0.88 , indicating that EI has significantly improved the $\mathrm{NO}_{x}$ and $\mathrm{SO}_{2}$ emission estimates. 

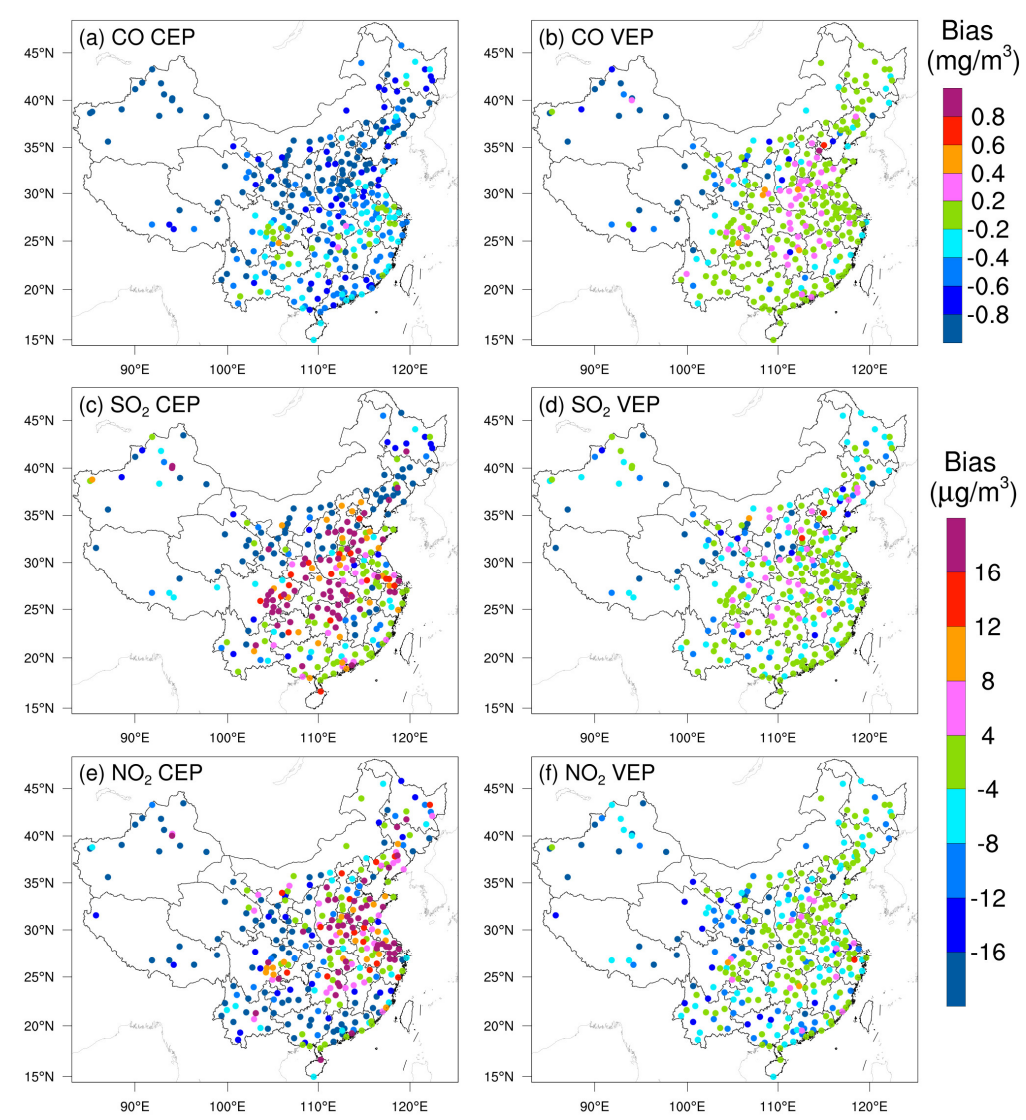

605 Figure 5. Spatial distribution of the BIAS of the simulated (a, b) CO, (c, d) $\mathrm{SO}_{2}$ and (e, 606 f) $\mathrm{NO}_{2}$ with prior (left, $\mathrm{CEP}$ ) and posterior (right, VEP) emissions. $\mathrm{CO}$ unit: $\mathrm{mg} \mathrm{m}^{-3}$; $607 \quad \mathrm{SO}_{2}$ and $\mathrm{NO}_{2}$ units: $\mu \mathrm{g} \mathrm{m} \mathrm{m}^{-3}$.

Figure 6 shows the spatial distributions of the mean biases of simulated $\mathrm{PM}_{2.5}$ and $\mathrm{PMC}$ evaluated against the assimilated observations. Similarly, the CEP simulations do not perform well. There are widespread underestimations across the country, with mean biases of -24.0 and $-32.4 \mu \mathrm{g} \mathrm{m}^{-3}$. After data assimilation, the performance of VEP simulations is significantly improved. The biases decrease by $72.1 \%$ and $90.4 \%$ to -6.7 and $-3.1 \mu \mathrm{g} \mathrm{m}^{-3}$, the RMSEs decrease by $41.2 \%$ and $40.7 \%$ to 29.6 and $24.6 \mu \mathrm{g} \mathrm{m}^{-3}$, and the CORRs increase by $35.9 \%$ and $176.0 \%$ to 0.87 and 0.69 for $\mathrm{PM}_{2.5}$ and $\mathrm{PMC}$, respectively. Overall, $89.6 \%$ and $97.2 \%$ of the assimilation sites are improved for $\mathrm{PM}_{2.5}$ 
and PMC, respectively. However, compared with the results of the 3 gaseous pollutants, potential overadjusted or contradictory adjustments of emissions as in the 3 gas species, it may be also related to the complex precursors and the nonlinear responses to its precursors for $\mathrm{PM}_{2.5}$, and the fact that we do not simulate the time variation of dust blowing caused by wind speed for PMC due to the lack of land cover data that is compatible with the CMAQ dust module and agricultural activities data to identify dust source regions.
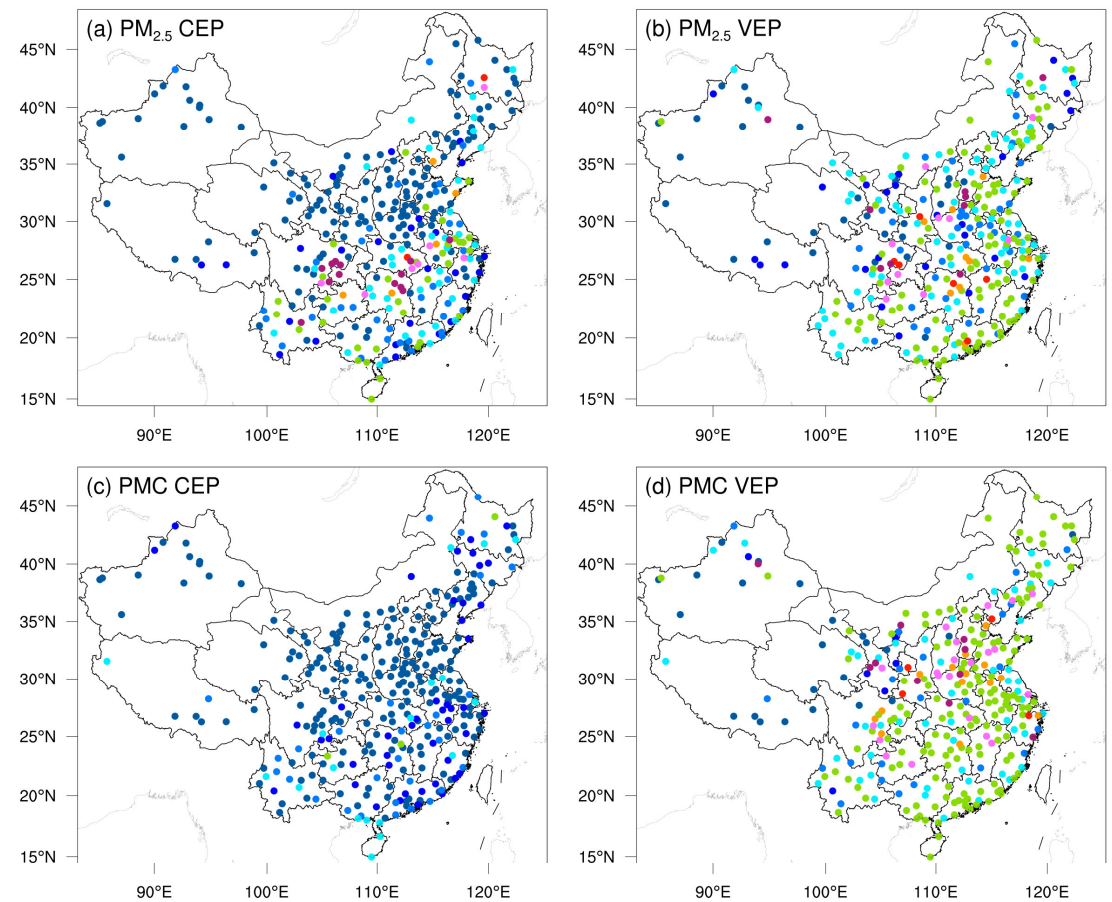

624

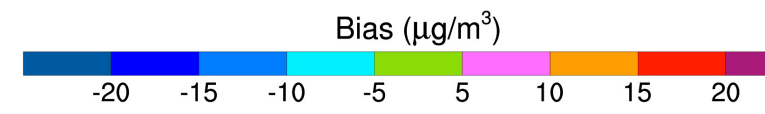

Figure 6. Same as in Fig. 5 but for $\mathrm{PM}_{2.5}$ and PMC. 
ratios of RMSEs range from $26.7 \%$ to $42.0 \%$, and the CORRs increase by $13.7-59.0 \%$

to $0.62-0.87$. Overall, the biases at the independent sites are similar or slightly worse

than those at the assimilated sites, which is reasonable since the closer to the assimilated site the independent sites are, the more constraints of observation information can be obtained, and the improvements in optimized state variables of the model are more significant. For example, generally, the transmission distance of $\mathrm{NO}_{2}$ is relatively short, and remote cities with small emission correlations to the cities with assimilated
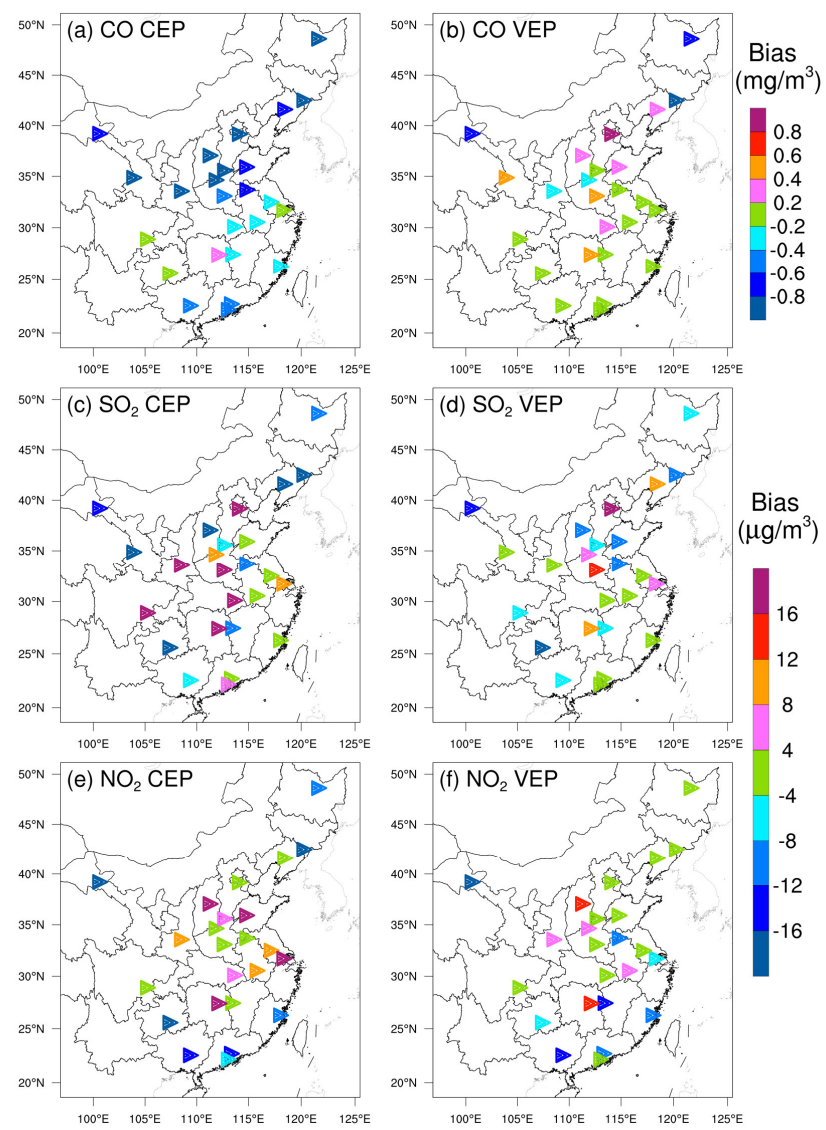

Figure 7. As in Fig. 5 but for the independent validation. 

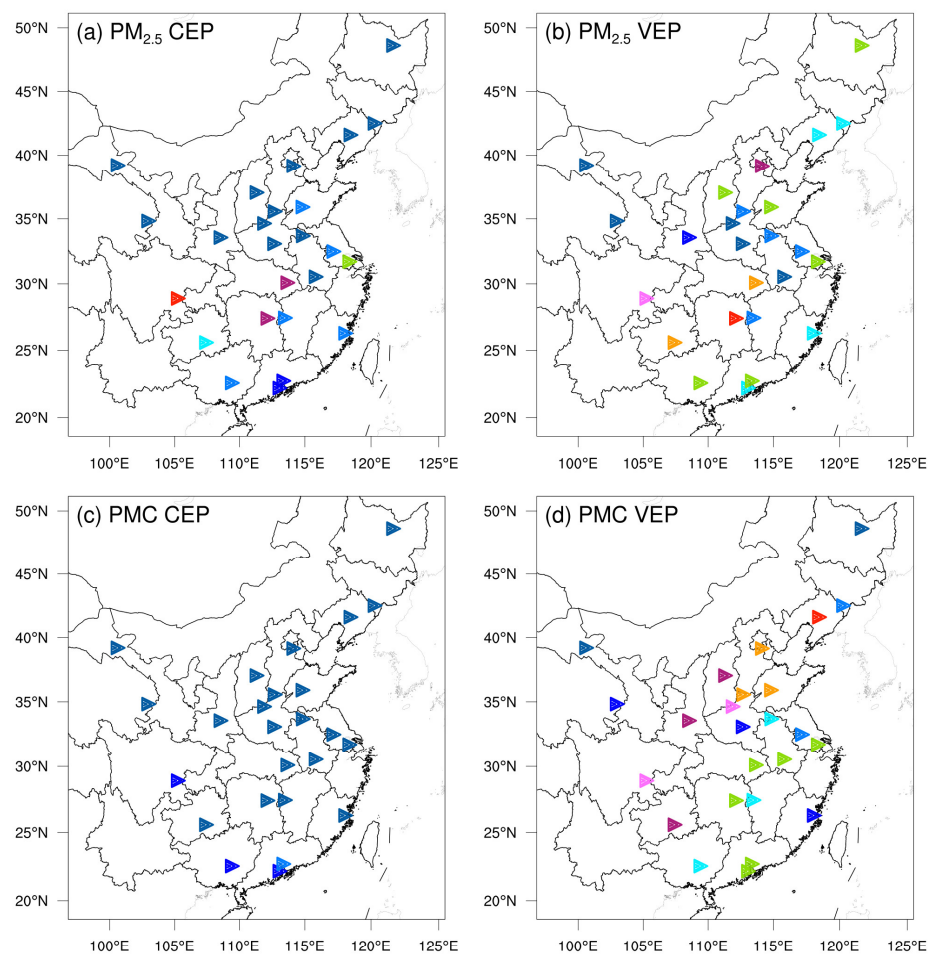

$\operatorname{Bias}\left(\mu \mathrm{g} / \mathrm{m}^{3}\right)$

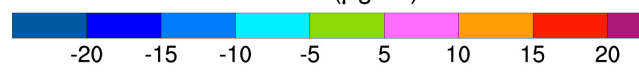

639

Figure 8. As in Fig. 6 but for the independent validation.

Compared with the previous studies, Tang et al. (2013) conducted inversion of CO emissions over Beijing and the surrounding areas, the improvements (Table 6) in the RMSE (37-48\% vs. 30-51\%) and the CORR (both studies 0.81) are comparable, but the biases here could decrease by $90-97 \%$, which is much greater than their $48-64 \%$ reductions. Additionally, Chen et al. (2019) showed that the RMSE of simulated $\mathrm{SO}_{2}$ with updated $\mathrm{SO}_{2}$ emissions decreased by $4.2-52.2 \%$ for different regions, and the CORR only increased to 0.69 at most. The improvement is relatively smaller than our results, which may be due to the insufficient adjustment of emissions caused by the underestimated ensemble spread through the inflation method. The better performance in this study may be related to our inversion process that makes the optimized emissions 
of the current DA window propagate to the next DA window for further correction.

Table 6. Statistics comparing the pollution concentrations from the simulations with prior (CEP) and posterior (VEP) emissions against assimilated and independent observations, respectively. $\mathrm{CO}$ unit: $\mathrm{mg} \mathrm{m}^{-3}$; others units: $\mu \mathrm{g} \mathrm{m}^{-3}$.

\begin{tabular}{|c|c|c|c|c|c|c|c|c|c|}
\hline \multirow{2}{*}{ Species } & \multirow{2}{*}{$\begin{array}{l}\text { Mean } \\
\text { Obs. }\end{array}$} & \multicolumn{2}{|c|}{ Mean Sim. } & \multicolumn{2}{|c|}{ BIAS } & \multicolumn{2}{|c|}{ RMSE } & \multicolumn{2}{|c|}{ CORR } \\
\hline & & CEP & VEP & CEP & VEP & CEP & VEP & CEP & VEP \\
\hline \multicolumn{10}{|c|}{ Against assimilated observations } \\
\hline $\mathrm{CO}$ & 1.43 & 0.66 & 1.36 & -0.77 & -0.08 & 1.08 & 0.56 & 0.46 & 0.81 \\
\hline $\mathrm{SO}_{2}$ & 32.5 & 34.4 & 28.4 & 1.9 & -4.1 & 42.4 & 17.7 & 0.39 & 0.88 \\
\hline $\mathrm{NO}_{2}$ & 43.8 & 40.8 & 39.0 & -2.9 & -4.8 & 25.0 & 12.3 & 0.65 & 0.88 \\
\hline $\mathrm{PM}_{2.5}$ & 77.0 & 53.1 & 70.3 & -24.0 & -6.7 & 50.3 & 29.6 & 0.64 & 0.87 \\
\hline PMC & 40.5 & 8.1 & 37.5 & -32.4 & -3.1 & 41.5 & 24.6 & 0.25 & 0.69 \\
\hline \multicolumn{10}{|c|}{ Against independent observations } \\
\hline $\mathrm{CO}$ & 1.54 & 0.79 & 1.52 & -0.75 & -0.02 & 1.15 & 0.72 & 0.59 & 0.82 \\
\hline $\mathrm{SO}_{2}$ & 40.6 & 39.2 & 37.3 & -1.3 & -3.2 & 44.3 & 27.2 & 0.57 & 0.87 \\
\hline $\mathrm{NO}_{2}$ & 50.2 & 50.0 & 47.5 & -0.3 & -2.7 & 21.7 & 15.9 & 0.73 & 0.83 \\
\hline $\mathrm{PM}_{2.5}$ & 91.5 & 64.6 & 84.1 & -26.9 & -7.4 & 64.1 & 37.2 & 0.62 & 0.87 \\
\hline PMC & 42.0 & 9.2 & 40.4 & -32.8 & -1.6 & 39.3 & 26.6 & 0.39 & 0.62 \\
\hline
\end{tabular}

* BIAS, mean bias; RMSE, root mean square error; CORR, correlation coefficient

\subsubsection{Uncertainty reduction}

The uncertainty reduction rate (UR) is another important quantity to evaluate the performance of RAPAS and the effectiveness of in-situ observations in this system (Chevallier et al., 2007; Jiang et al., 2021; Takagi et al., 2011). Following Jiang et al. (2021), the UR is calculated as

$$
U R=\left(1-\frac{\sigma_{\text {posterior }}}{\sigma_{\text {prior }}}\right) \times 100
$$

where $\sigma_{\text {posterior }}$ and $\sigma_{\text {prior }}$ are the posterior and prior uncertainties, respectively. Figure 9 shows the URs averaged in each province and the whole mainland China. The URs vary with species, and among the 5 species of emissions, the uncertainties of the $\mathrm{PPM}_{2.5}$ and PMC are greatly reduced, while the UR of $\mathrm{NO}_{x}$ emission is lowest, that is because the URs are closely related to the magnitude settings of prior uncertainties (Jiang et al., 2021). For the whole mainland China, the uncertainties are reduced by 
$66844.4 \%, 45.0 \%, 34.3 \%, 51.8 \%$ and $56.1 \%$ for $\mathrm{CO}, \mathrm{SO}_{2}, \mathrm{NO}_{x}, \mathrm{PPM}_{2.5}$ and $\mathrm{PMC}$,

669 respectively. For one species, it also varies across provinces. The URs are usually

670 related to observation coverage, which means that the more observation constraints

671 there are, the more the URs decrease. Additionally, the URs may also relate to emission

672 distributions. Generally, the URs are more significant in the provinces where the

673 observations and emissions are both relatively concentrated (e.g., Tibet), while they are

674 much lower in where the emissions are scattered or relatively uniform, but the

675 observations are only in large cities, even though there are many more observations

676 than other provinces. 
Uncertainty reduction (\%)

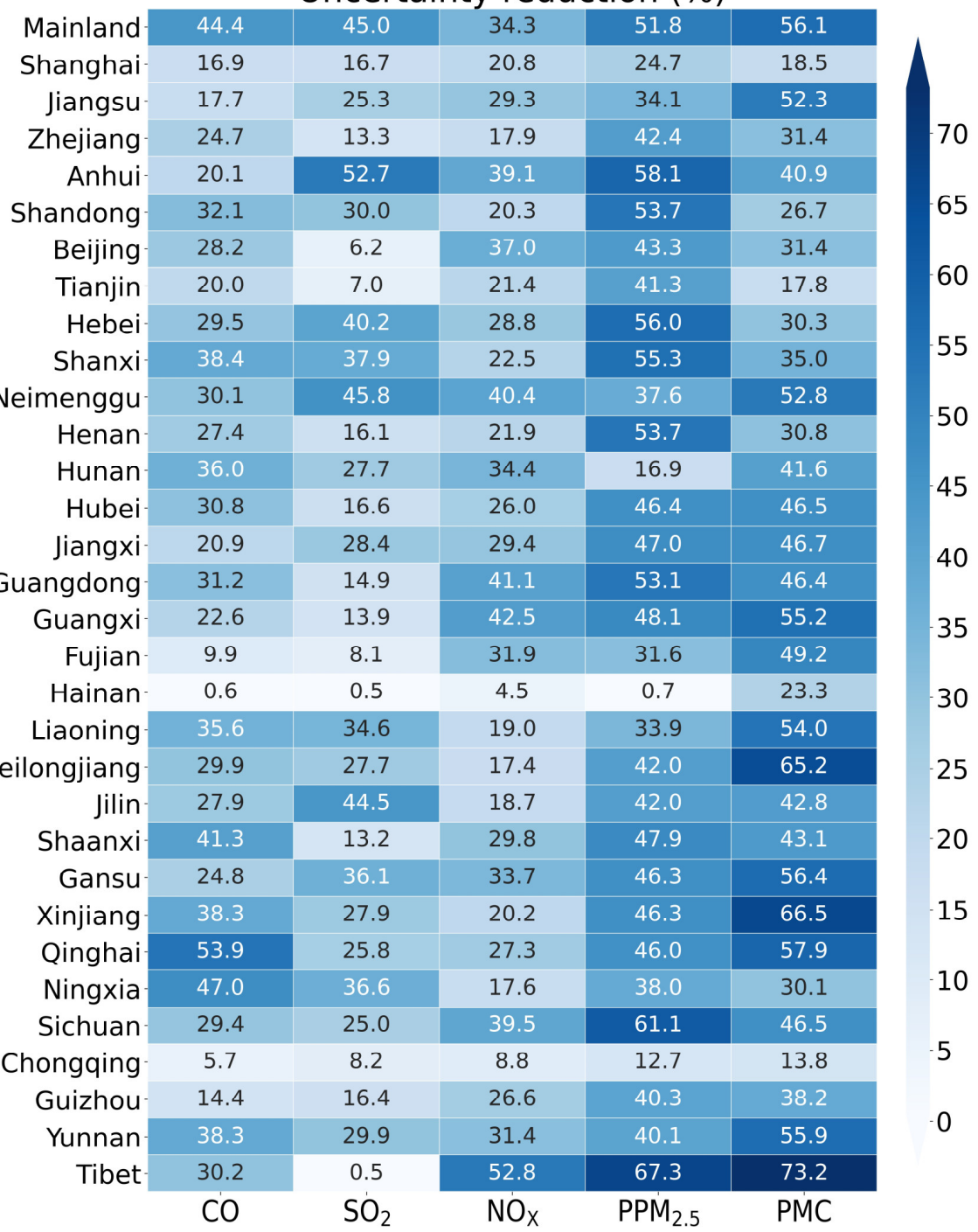

Figure 9. Time-averaged posterior emission uncertainty reduction (\%) indicated by the

679 standard deviation reduction of total emissions per province calculated by prior and 680 posterior ensembles.

\subsection{Inverted emissions}

682 Figure 10 shows the spatial distribution of the temporal averaged prior and posterior

683 emissions and their differences. Higher emissions are mainly concentrated in central 
and eastern China, especially in the NCP, YRD, and PRD, and lower emissions occur across Northwest and Southern China. Compared with the prior emissions, posterior CO emissions are considerably increased across most areas of mainland China, especially in northern China, with an overall increase of $129 \%$. Notable underestimation of the prior emissions is also confirmed by previous inversion estimations (Feng et al., 2020b; Tang et al., 2013; Wu et al., 2020) and model evaluations (Kong et al., 2019a). For $\mathrm{SO}_{2}$, the emission increases mainly occur in Northeast China, Shanxi, Ningxia, Gansu, Fujian, Jiangxi and Yunnan provinces. In SCB, Central China, YRD, and part of NCP, the emissions are significantly reduced. For national total, the $\mathrm{SO}_{2}$ emission is increased by $20 \%$. For $\mathrm{NO}_{x}$, although the increment of national total emissions is small, only about 5\%, large deviations still exist on regional scale. Obviously, the emissions in the NCP and YRD are reduced, while in the other regions, the emissions of most cities are increased. The changes in $\mathrm{PPM}_{2.5}$ emission are similar to $\mathrm{SO}_{2}$. Compared with the prior emission, the posterior $\mathrm{PPM}_{2.5}$ emissions are decreased over central China, SCB and YRD, while the ones in southern and northern China are increased, especially in Shanxi, Shaanxi, Gansu and southern Hebei province. Overall, the relative increase is $95 \%$. For PMC, the posterior emissions are increased over the whole mainland China, with national mean relative increase exceeding $1000 \%$. Larger emission increments mainly occur in the areas where have significant anthropogenic emissions of $\mathrm{CO}$ and $\mathrm{PPM}_{2.5}$, indicating that the large underestimations of PMC emissions in the prior inventory may be mainly attributed to the underestimations of anthropogenic activities. In addition, without dust may be another reason, since no wind blowing dust scheme was applied in this study as mentioned above. Large PMC emission increment are also found in Ma et al (2019). Detailed estimation of posterior emissions and relative changes compared to prior emissions in each province and the whole mainland China is given in Table S1. Note that the differences, excluding PMC, between the prior and posterior emissions mainly reflect the deficiencies of the prior emissions because the times of the prior emissions and the observations are completely consistent in this study. 

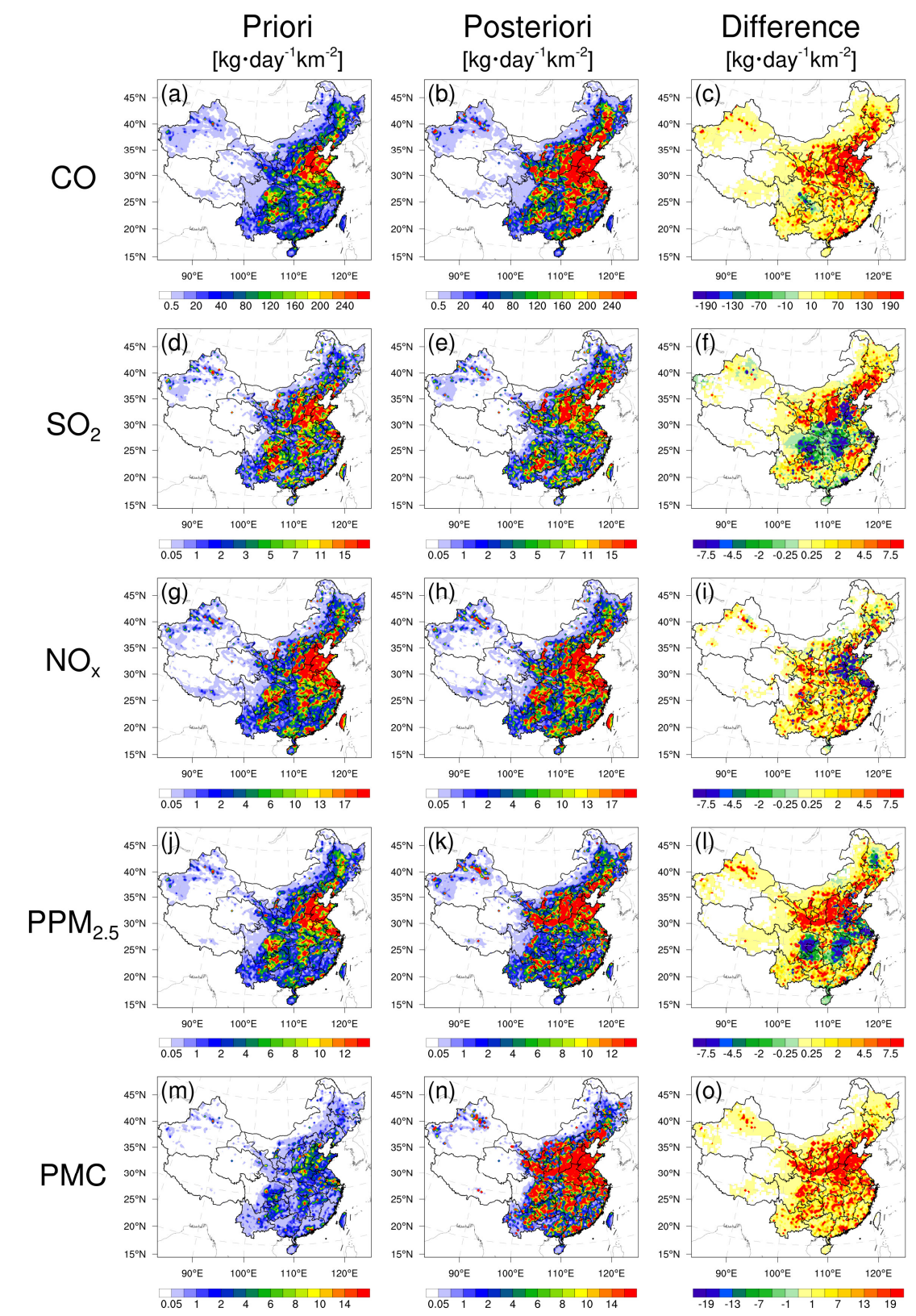

714 Figure 10. Spatial distribution of the time-averaged prior emissions (left column, MEIC

715 2016), posterior emissions (middle column), and differences (right column, posterior 716 minus prior). 


\subsection{Sensitivity tests}

\subsubsection{The advantages of "two-step" scheme}

Adjusting the ICs and emissions simultaneously (i.e., "one-step" scheme) has been applied to constrain prior emissions in many previous studies (Evensen, 2009; Kong et al., 2019b). To investigate the impact of different methods on the optimized emissions, a sensitivity test (EMS1) is performed, in which the initial fields of each DA window are optimized using the 3DVAR algorithm directly. Compared with our "two-step" method (EMDA), the posterior emissions of EMS1 are increased by $7 \%, 1.4 \%, 0.6 \%$, 22.2\%, and $17.2 \%$ for $\mathrm{CO}, \mathrm{SO}_{2}, \mathrm{NO}_{x}, \mathrm{PM}_{2.5}$ and $\mathrm{PMC}$, respectively. As mentioned previously, in the "two-step" scheme, the optimized emission can be sufficiently fed back to the concentration field and fully mixed in the atmosphere (1 day), and the error transfer makes the system consistently and stably updated. If the emission in one window is overestimated, in this way, it could be compensated in the next window with lower estimates. In contrast, when initial fields assimilating with observations simultaneously at each window, the overestimation will not be corrected and will accumulate to the end. We also evaluate the posterior emissions of EMS1 using the same method as shown in Sect. 4.1.3. Figure 11 shows the time series of simulated and observed daily concentrations and their RMSEs verified against the assimilated sites. Overall, compared to the base experiment (EMDA), the performance of EMS1 is significantly worse, with RMSEs of $\mathrm{CO}, \mathrm{SO}_{2}, \mathrm{NO}_{2}, \mathrm{PM}_{2.5}$ and $\mathrm{PMC}$ increasing from $0.56 \mathrm{mg} \mathrm{m}^{-3}, 17.7,12.3,29.6$, and $24.6 \mu \mathrm{g} \mathrm{m}^{-3}$ to $0.69 \mathrm{mg} \mathrm{m}^{-3}, 18.8,13.3,36.8$, and 33.3 $\mu \mathrm{g} \mathrm{m} \mathrm{m}^{-3}$, respectively. Additionally, it can be seen from the figure that the results of the two experiments are relatively close at the beginning and during the heavy pollution period (16-21 December). However, after that, the simulated results with "one-step" inversion emissions are significantly higher than the observations, and these large biases continue until the end. The results verified against the independent sites also show a similar situation (Fig. S2). The reason may be that during the period of heavy pollution, the WRF-CMAQ (off-line model) does not consider the feedback process of meteorology and chemistry, resulting in low simulations. Therefore, the system will 
compensate for the underestimated concentrations caused by the model error through more emissions, resulting in the overestimation of emissions. The accumulation of emission error in each independent window further leads to the overestimation of concentration after the end of high pollution, especially for species with a long lifetime (e.g., CO). On the contrary, this overestimation will be corrected quickly in the subsequent inversion using the "two-step" inversion scheme in this study, so as to ensure the stability of the system. It should be noted that the model performance depends on many factors but does not affect the advantage of the "two-step" scheme.
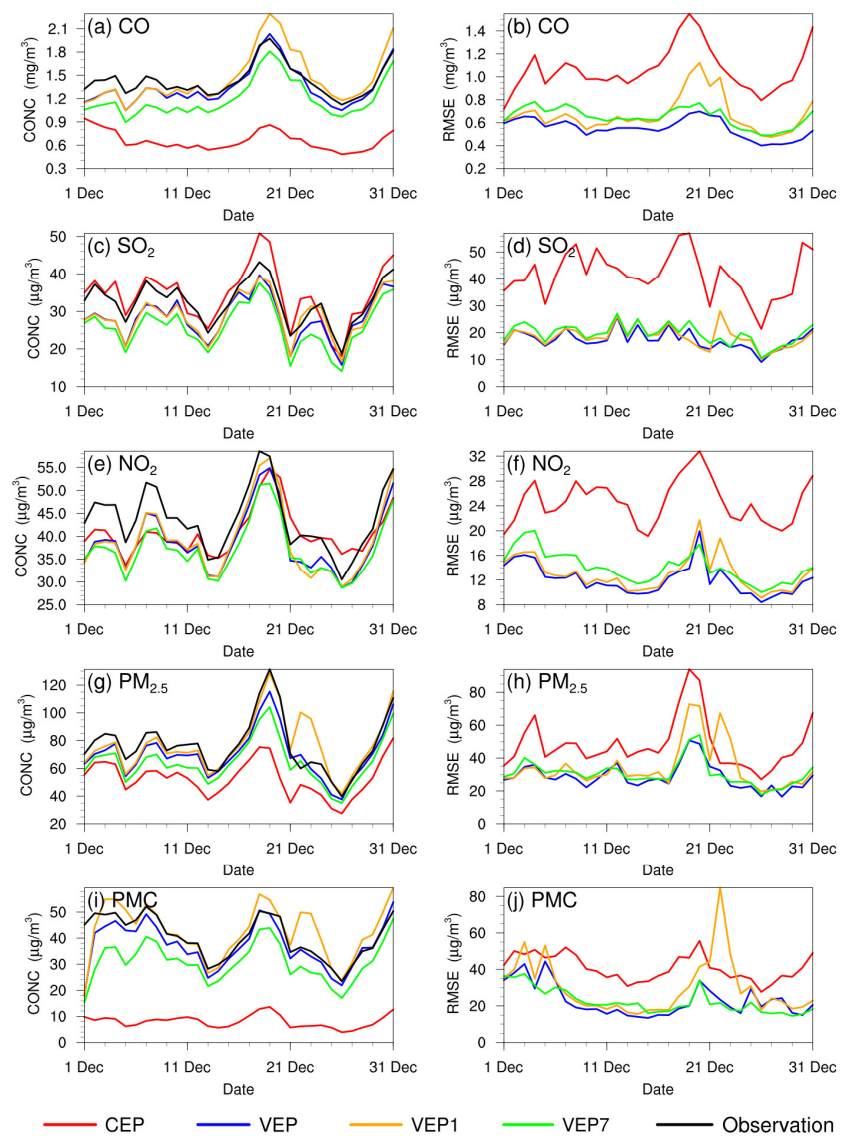

Figure 11. Time series of the daily concentrations (CONC, left) and root mean square error (RMSE, right) obtained from CEP, VEP, VEP1, and VEP3. The simulations were verified against the assimilated sites. 


\subsubsection{Impact of prior inventories}

Various prior inventories have great differences in space allocation and emission magnitude. Inversion results can be sensitive to a priori emissions if the observation is insufficient (Gurney et al., 2004; He et al., 2018). MEIC 2012 is used as an alternative a priori in EMS2 to investigate the impact of different prior emissions on the posteriori. Figure 12 shows the time series of the relative differences in daily posterior emissions of the five species between the EMDA (base) and EMS2 experiments. Overall, the differences between the two posterior emissions gradually decrease over time. At the beginning, the differences in the $\mathrm{CO}, \mathrm{SO}_{2}, \mathrm{NO}_{\mathrm{x}}, \mathrm{PPM}_{2.5}$ and $\mathrm{PMC}$ between the two inventories (i.e., MEIC 2012 vs MEIC 2016) are 17.5\%, 114.5\%, 30.8\%, 46.0\% and $72.0 \%$, respectively, while during the last ten days, the differences of the two posterior emissions have decreased to $2.5 \%, 4.5 \%, 4.5 \%,-8.9 \%$ and $3.0 \%$, respectively. In addition, it also could be found that the species that has larger emission differences at the beginning take a longer time (namely more DA steps) to achieve convergence. The quick convergence of PMC emission is attributed to the large prior uncertainty of $100 \%$ used in the first 3 DA windows. Different from the other species, there are significant negative deviations of $\mathrm{PPM}_{2.5}$ emissions between the two experiments. That may be due to the positive deviations in the precursors of $\mathrm{PM}_{2.5}$ (i.e., $\mathrm{SO}_{2}$ and $\mathrm{NO}_{x}$ ), which will lead to a larger amount of secondary production. To balance the total $\mathrm{PM}_{2.5}$ concentration, the $\mathrm{PPM}_{2.5}$ emissions will be reduced. We compare the $\mathrm{PM}_{2.5}$ concentrations simulated by the two optimized inventories and find that they are almost the same (Fig. S3). Overall, this indicates that the observation in China is sufficient in inferring the emissions, and our system is rather robust. Meanwhile, it also suggests that the monthly posterior emissions shown in Sect. 4.2 are still underestimated to a certain extent. 


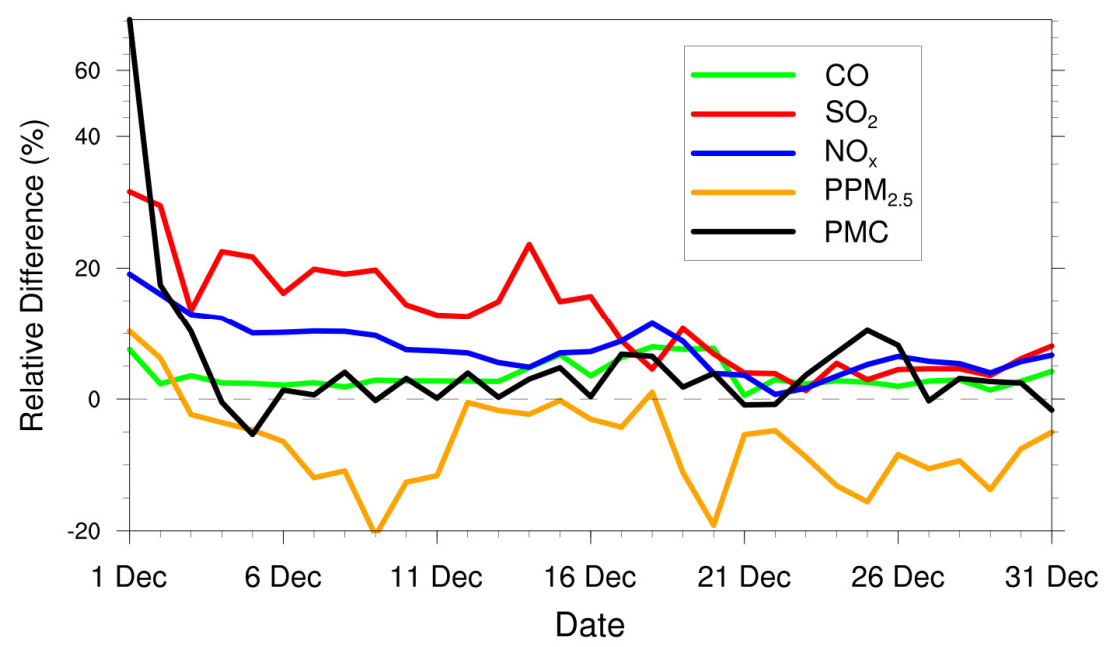

Figure 12. Relative differences in $\mathrm{CO}, \mathrm{SO}_{2}, \mathrm{NO}_{x}, \mathrm{PPM}_{2.5}$ and $\mathrm{PMC}$ emissions $(\%$, the ratio of absolute difference to EMDA) between the EMDA and EMS2 experiments.

\subsubsection{Impact of prior uncertainties settings}

The uncertainty of prior emissions determines how closely the analysis is weighted toward the background and observation, but information about prior uncertainties is generally not readily available. To evaluate the possible influence of prior uncertainties on the optimized emissions, we increased/reduced the uncertainties after 3 days of cycling, namely starting at 0000 UTC, 3 December, by $25 \%$ and $50 \%$ in EMS3 (-50\%), EMS4 (-25\%), EMS5 (+25\%) and EMS6 (+50\%), respectively. Table 7 summarizes the emission changes with different prior uncertainties settings in EMS3-6 experiments. To better understand the response of the system to the emission uncertainty settings, Fig. 13 shows the time series of $\mathrm{SO}_{2}$ emission changes and the RMSEs of simulated $\mathrm{SO}_{2}$ with emissions updated in the EMDA and EMS3-6 experiments over the YRD and NCP (Fig. 2). Compared with the EMDA, when the uncertainties are decreased (increased), the emissions of the 5 species decrease (increase) accordingly. That is because the posterior emissions of the 5 species are larger than the prior emissions, and as shown in Fig. 13, larger uncertainty will lead to a faster convergence, resulting in larger 
802 posterior emissions. It also could be found from Fig. 13 that a faster convergence will

803 indeed reduce the RMSE of the simulated concentration with the posterior emissions in

804 the early stage of the experiment, but in the later stage of the experiment, there are no

805 significant differences for the RMSE among the different experiments. In addition, it

806 shows that when greater uncertainties are set, the day-to-day changes in emissions are

807 also more drastic, resulting in a larger RMSE as shown in NCP. Moreover, those

808 significant day-to-day variations of estimated emissions may not be in line with the

809 actual situation. Overall, the uncertainties chosen in EMDA aim to minimize the

810 deviation of the concentration fields and maintain the stability of inversion.

811 Table 7. Relative differences in $\mathrm{CO}, \mathrm{SO}_{2}, \mathrm{NO}_{x}, \mathrm{PPM}_{2.5}$ and $\mathrm{PMC}$ emissions (\%, the ratio of absolute difference to EMDA) between the EMDA and EMS3-6 experiments.

\begin{tabular}{ccccc}
\hline Species & EMS3 & EMS4 & EMS5 & EMS6 \\
\hline $\mathrm{CO}$ & -8.6 & -4 & 3 & 5.2 \\
$\mathrm{SO}_{2}$ & -14 & -5.7 & 3.6 & 6.8 \\
$\mathrm{NO}_{x}$ & -6.5 & -3 & 2.8 & 4.5 \\
$\mathrm{PPM}_{2.5}$ & -16.5 & -7.8 & 4.6 & 8.7 \\
$\mathrm{PMC}$ & -18.5 & -8.2 & 7.3 & 13.1 \\
\hline
\end{tabular}



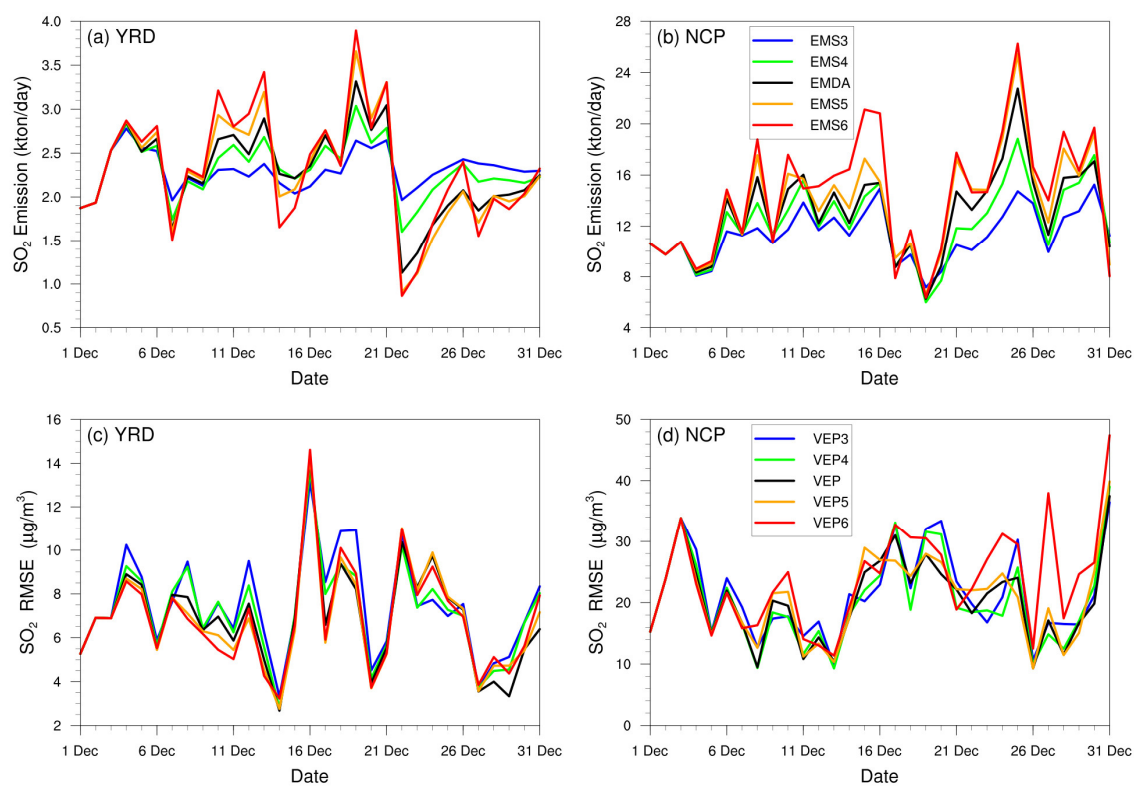

Figure 13. Time-series of $\mathrm{SO}_{2}$ emissions changes and the RMSE of simulated $\mathrm{SO}_{2}$ with updated $\mathrm{SO}_{2}$ emissions in the EMDA and EMS3-6 experiments over the Yangtze River Delta (YRD) and North China Plain (NCP).

\subsubsection{Impact of observation error settings}

Another factor that determines the relative weights of the observation and background in the analysis is observation errors. A proper estimate of the observation error is also important in regard to the filter performance, but observation errors are not provided with the dataset. The observation error is usually set to a fixed value (Ma et al., 2019), a specific proportion of the observation value (Tang et al., 2013) or the value calculated by combining measurement error with representative error as used in this study. Generally, the performance of the data assimilation is quite sensitive to the specification of observation error (Tang et al., 2013). To evaluate the influence of observation error on the optimized emissions, a sensitivity experiment (EMS7) with doubled observation error was conducted. Overall, the spatial distribution of emissions after optimization is almost the same as that of the EMDA experiment, but the increment is lower (Fig. S4), 
resulting in a weaker estimate of the national total emission for each species. That is because that the observation error becomes large, the system will be more convinced of the prior emission and reduce the effect of observation information. The simulations in VEP7 usually perform worse, with larger biases and RMSEs than those of VEP (Figs 11, S2 and S5), especially in most of western and southern China where posterior emissions are still significantly underestimated, suggesting that too large observation error may substantially impact the estimated emissions.

\section{Summary and conclusions}

In this study, we developed a Regional multi-Air Pollutant Assimilation System (RAPASv1.0) based on the WRF/CMAQ model, 3DVAR and EnKF algorithm. RAPAS can quantitatively optimize gridded emissions of $\mathrm{CO}, \mathrm{SO}_{2}, \mathrm{NO}_{x}, \mathrm{PPM}_{2.5}$ and $\mathrm{PMC}$ on regional scale by simultaneously assimilating hourly in-situ measurements of $\mathrm{CO}, \mathrm{SO}_{2}$, $\mathrm{NO}_{2}, \mathrm{PM}_{2.5}$ and $\mathrm{PM}_{10}$. This system includes two subsystems, namely the IA subsystem and the EI subsystem, which optimizes the chemical ICs, and infers the anthropogenic emissions, respectively.

Taking the 2016 Multi-resolution Emission Inventory for China (MEIC 2016) in December as a priori, the emissions of $\mathrm{CO}, \mathrm{SO}_{2}, \mathrm{NO}_{x}, \mathrm{PPM}_{2.5}$ and $\mathrm{PMC}$ in December 2016 were inferred through assimilating the corresponding nationwide observations over China. The optimized ICs and posterior emissions were examined against the assimilated and independent observations through parallel forward simulation experiments with and without DA. Sensitivity tests are also performed to investigate the impact of different inversion processes, prior emissions, prior uncertainties and observation errors on the emission estimates.

The results show that RAPAS can significantly improve the simulations and reduce the uncertainties of the emissions. For the whole mainland China, the emission uncertainties reduced by $44.4 \%, 45.0 \%, 34.3 \%, 51.8 \%$ and $56.1 \%$ for $\mathrm{CO}, \mathrm{SO}_{2}, \mathrm{NO}_{x}$, $\mathrm{PPM}_{2.5}$ and PMC, respectively, the RMSEs of the simulated concentrations with posterior emissions decreased by $40.1-56.3 \%$, and the CORRs increased from $0.26-0.66$ 
to $0.69-0.87$ for different species. Overall, compared with the prior emissions (MEIC 2016), the posterior emissions increased by $129 \%, 20 \%, 5 \%$ and $95 \%$ for $\mathrm{CO}, \mathrm{SO}_{2}, \mathrm{NO}_{x}$ and $\mathrm{PPM}_{2.5}$, respectively. The posterior PMC emissions, which included anthropogenic and natural dust contributions, increased by $1045 \%$. The sensitivity tests with different inversion processes show that the "two-step" scheme in emission inversion outperforms the joint adjustment of ICs and emissions ("one-step" scheme), especially after heavy pollution. The sensitivity tests with different prior inventories show the observation in China is sufficient in inferring the emissions, and our system is less dependent on prior inventories. Additionally, the sensitivity tests with different prior uncertainties indicate that when the posterior emissions are larger than the prior emissions, the emissions decrease/increase with the decreases/increases of uncertainties because of the different convergence rates. These results demonstrate the advantage of the two-step method in emission inversion in that the inversion errors of the last window could be transferred to the current window for further optimization and the robustness of the emissions estimated from RAPAS using the nationwide observations over China. It should be noted that the system usually responds slowly to too small a priori uncertainty or too large observation error, which may result in large errors in the estimated emissions.

Independent variable localization was adopted to avoid potential spurious correlations across different species in this study. However, the transmission scales for different species in different regions are still different, and a more accurate localization range could be obtained through backward trajectory analysis. In additionally, $\mathrm{O}_{3}$ observations are not assimilated to improve $\mathrm{NO}_{x}$ and $\mathrm{VOC}$ emissions using crossspecies information due to the strong nonlinear effects within the $\mathrm{O}_{3}-\mathrm{NO}_{x}-\mathrm{VOC}$ relationship, in which the $\mathrm{O}_{3}$ concentration and $\mathrm{NO}_{x}$ (VOC) emissions are positively correlated in the $\mathrm{NO}_{x}$ (VOC)-limited region and negatively correlated in the VOC $\left(\mathrm{NO}_{x}\right.$ )-limited region (Tang et al., 2011). This work will be followed up by an ongoing work using available VOC observations. As shown previously, the concentrations after DA are obviously underestimated in western China, indicating that the inverted emissions over these regions still have large uncertainties because of the sparsity of 
observations that are spatially insufficient for sampling the inhomogeneity of emissions.

In summary, this study offers a useful tool for accurately quantifying multi-species anthropogenic emissions at large scales and near-real time, which will serve better for monitoring emission changes and designing future emissions regulations and pollution control.

\section{Code and data availability}

The WRF model code is open-source code and can be obtained from the WRF Model User's Page (https://www2.mmm.ucar.edu/wrf/users, last access: 25 April 2021). The CMAQ model is available through an open license as well (https://www.epa.gov/cmaq, last access: 25 April 2021). The observation and emission data used in this paper are available at https://doi.org/10.5281/zenodo.4718290 (Feng and Jiang, 2021). The code of this system can be obtained on request from the corresponding author (jiangf@nju.edu.cn).

\section{Author contribution}

SF, FJ, ZW and ZJ developed RAPAS v1.0. SF and FJ designed the research. SF performed model simulations, analyzed data, and prepared the paper with contributions from all co-authors. FJ supervised the model development project and assisted in conceptualization and writing. HW, WH, YS, LZ, YZ, CL, and WJ contributed to the discussion and improvement of the paper.

\section{Competing interests}

The authors declare that they have no conflict of interest. 


\begin{abstract}
913 Acknowledgements
914 This work is supported by the National Key R\&D Program of China (Grant No. 915 2016YFA0600204), the National Natural Science Foundation of China (Grant No. 916 41907378), and the Nanjing University Innovation and Creative Program for Ph.D. candidate (Grant No. CXCY19-60). We are grateful to the High Performance Computing Center (HPCC) of Nanjing University for doing the numerical calculations in this paper on its blade cluster system, and thank the MEIC team for providing the prior anthropogenic emissions (http://www.meicmodel.org/).
\end{abstract}

\section{References}

Appel, K. W., Pouliot, G. A., Simon, H., Sarwar, G., Pye, H. O. T., Napelenok, S. L., Akhtar, F., and Roselle, S. J.: Evaluation of dust and trace metal estimates from the Community Multiscale Air Quality (CMAQ) model version 5.0, Geoscientific Model Development, 6, 883-899, 10.5194/gmd-6-883-2013, 2013.

Bauwens, M., Compernolle, S., Stavrakou, T., Müller, J.-F., van Gent, J., Eskes, H., Levelt, P. F., van der A, R., Veefkind, J. P., Vlietinck, J., Yu, H., and Zehner, C.: Impact of Coronavirus Outbreak on NO2 Pollution Assessed Using TROPOMI and OMI Observations, 47, e2020GL087978, 10.1029/2020g1087978, 2020.

Binkowski, F. S. and Roselle, S. J.: Models-3 community multiscale air quality (CMAQ) model aerosol component - 1. Model description, Journal of Geophysical Research-Atmospheres, 108, 10.1029/2001jd001409, 2003.

Bruhwiler, L. M. P., Michalak, A. M., Peters, W., Baker, D. F., and Tans, P.: An improved Kalman Smoother for atmospheric inversions, Atmos. Chem. Phys., 5, 2691-2702, 10.5194/acp-5-2691$2005,2005$.

Chen, D., Liu, Z., Ban, J., and Chen, M.: The 2015 and 2016 wintertime air pollution in China: SO2 emission changes derived from a WRF-Chem/EnKF coupled data assimilation system, Atmospheric Chemistry and Physics, 19, 8619-8650, 10.5194/acp-19-8619-2019, 2019.

Chen, D., Liu, Z., Fast, J., and Ban, J.: Simulations of sulfate-nitrate-ammonium (SNA) aerosols during the extreme haze events over northern China in October 2014, Atmospheric Chemistry and Physics, 16, 10707-10724, 10.5194/acp-16-10707-2016, 2016.

Chevallier, F., Bréon, F.-M., and Rayner, P. J.: Contribution of the Orbiting Carbon Observatory to the estimation of $\mathrm{CO} 2$ sources and sinks: Theoretical study in a variational data assimilation framework, 112, 10.1029/2006JD007375, 2007.

Clements, A. L., Fraser, M. P., Upadhyay, N., Herckes, P., Sundblom, M., Lantz, J., and Solomon, P. A.: Chemical characterization of coarse particulate matter in the Desert Southwest - Pinal County Arizona, USA, Atmospheric Pollution Research, 5, 52-61, 10.5094/apr.2014.007, 2014.

Clements, N., Hannigan, M. P., Miller, S. L., Peel, J. L., and Milford, J. B.: Comparisons of urban and rural PM10-2.5 and PM2.5 mass concentrations and semi-volatile fractions in northeastern 
de Foy, B., Lu, Z., Streets, D. G., Lamsal, L. N., and Duncan, B. N.: Estimates of power plant NOx emissions and lifetimes from OMI NO2 satellite retrievals, Atmospheric Environment, 116, 1-11, 10.1016/j.atmosenv.2015.05.056, 2015.

Descombes, G., Auligne, T., Vandenberghe, F., Barker, D. M., and Barre, J.: Generalized background error covariance matrix model (GEN_BE v2.0), Geoscientific Model Development, 8, 669-696, 10.5194/gmd-8-669-2015, 2015.

Ding, J., van der A, R. J., Mijling, B., Levelt, P. F., and Hao, N.: NOx emission estimates during the 2014 Youth Olympic Games in Nanjing, Atmospheric Chemistry and Physics, 15, 9399-9412, 10.5194/acp-15-9399-2015, 2015.

Elbern, H., Strunk, A., Schmidt, H., and Talagrand, O.: Emission rate and chemical state estimation by 4-dimensional variational inversion, Atmospheric Chemistry and Physics, 7, 3749-3769, 10.5194/acp-7-3749-2007, 2007.

Evensen, G.: The Ensemble Kalman Filter for Combined State and Parameter Estimation MONTE CARLO TECHNIQUES FOR DATA ASSIMILATION IN LARGE SYSTEMS, Ieee Control Systems Magazine, 29, 83-104, 10.1109/mcs.2009.932223, 2009.

Feng, S., Jiang, F., Jiang, Z., Wang, H., Cai, Z., and Zhang, L.: Impact of 3DVAR assimilation of surface PM2.5 observations on PM2.5 forecasts over China during wintertime, Atmospheric Environment, 187, 34-49, 10.1016/j.atmosenv.2018.05.049, 2018.

Feng, S., Jiang, F., Wu, Z., Wang, H., Ju, W., and Wang, H.: CO Emissions Inferred From Surface CO Observations Over China in December 2013 and 2017, Journal of Geophysical ResearchAtmospheres, 125, 10.1029/2019jd031808, 2020a.

Feng, S., Jiang, F., Wang, H., Wang, H., Ju, W., Shen, Y., Zheng, Y., Wu, Z., and Ding, A.: NOx Emission Changes Over China During the COVID-19 Epidemic Inferred From Surface NO2 Observations, Geophysical Research Letters, 47, 10.1029/2020g1090080, 2020 b.

Feng, S. and Jiang, F.: Anthropogenic air pollutant emissions over China inferred by Regional multiAir Pollutant Assimilation System (RAPAS v1.0), Zenodo, 10.5281/zenodo.4718290, 2021.

Gaspari, G. and Cohn, S. E.: Construction of correlation functions in two and three dimensions, Quarterly Journal of the Royal Meteorological Society, 125, 723-757, 10.1256/smsqj.55416, 1999.

Guenther, A. B., Jiang, X., Heald, C. L., Sakulyanontvittaya, T., Duhl, T., Emmons, L. K., and Wang, X.: The Model of Emissions of Gases and Aerosols from Nature version 2.1 (MEGAN2.1): an extended and updated framework for modeling biogenic emissions, Geoscientific Model Development, 5, 1471-1492, 10.5194/gmd-5-1471-2012, 2012. Bruhwiler, L., Chen, Y. H., Ciais, P., Fung, I. Y., Heimann, M., John, J., Maki, T., Maksyutov, S., Peylin, P., Prather, M., and Taguchi, S.: Transcom 3 inversion intercomparison: Model mean results for the estimation of seasonal carbon sources and sinks, Global Biogeochemical Cycles, 18, 10.1029/2003gb002111, 2004.

He, W., van der Velde, I. R., Andrews, A. E., Sweeney, C., Miller, J., Tans, P., van der Laan-Luijkx, I. T., Nehrkorn, T., Mountain, M., Ju, W., Peters, W., and Chen, H.: CTDAS-Lagrange v1.0: a high-resolution data assimilation system for regional carbon dioxide observations, Geoscientific Model Development, 11, 3515-3536, 10.5194/gmd-11-3515-2018, 2018. 
Hinds, W.C.: Aerosol Technology: Properties, Behavior, and Measurement of Airborne Particles. New York: John Wiley, 1982.

Houtekamer, P. L. and Mitchell, H. L.: A sequential ensemble Kalman filter for atmospheric data assimilation, Monthly Weather Review, 129, 123-137, 10.1175/15200493(2001)129<0123:asekff>2.0.co;2, 2001.

Houtekamer, P. L. and Zhang, F.: Review of the Ensemble Kalman Filter for Atmospheric Data Assimilation, Monthly Weather Review, 144, 4489-4532, 10.1175/mwr-d-15-0440.1, 2016.

Jiang, F., Liu, Q., Huang, X., Wang, T., Zhuang, B., and Xie, M.: Regional modeling of secondary organic aerosol over China using WRF/Chem, Journal of Aerosol Science, 43, 57-73, 10.1016/j.jaerosci.2011.09.003, 2012a.

Jiang, F., Zhou, P., Liu, Q., Wang, T., Zhuang, B., and Wang, X.: Modeling tropospheric ozone formation over East China in springtime, Journal of Atmospheric Chemistry, 69, 303-319, 10.1007/s10874-012-9244-3, 2012b.

Jiang, F., Wang, H. M., Chen, J. M., Machida, T., Zhou, L. X., Ju, W. M., Matsueda, H., and Sawa, Y.: Carbon balance of China constrained by CONTRAIL aircraft CO2 measurements, Atmospheric Chemistry and Physics, 14, 10133-10144, 10.5194/acp-14-10133-2014, 2014.

Jiang, F., Wang, H., Chen, J. M., Ju, W., Tian, X., Feng, S., Li, G., Chen, Z., Zhang, S., Lu, X., Liu, J., Wang, H., Wang, J., He, W., and Wu, M.: Regional CO2 fluxes from 2010 to 2015 inferred from GOSAT XCO2 retrievals using a new version of the Global Carbon Assimilation System, Atmos. Chem. Phys., 21, 1963-1985, 10.5194/acp-21-1963-2021, 2021.

Jiang, W., Smyth, S., Giroux, E., Roth, H., and Yin, D.: Differences between CMAQ fine mode particle and PM2.5 concentrations and their impact on model performance evaluation in the lower Fraser valley, Atmospheric Environment, 40, 4973-4985, 10.1016/j.atmosenv.2005.10.069, 2006.

Jiang, Z., Liu, Z., Wang, T., Schwartz, C. S., Lin, H.-C., and Jiang, F.: Probing into the impact of 3DVAR assimilation of surface PM10 observations over China using process analysis, Journal of Geophysical Research: Atmospheres, 118, 6738-6749, 10.1002/jgrd.50495, 2013.

Jiang, Z., Worden, J. R., Worden, H., Deeter, M., Jones, D. B. A., Arellano, A. F., and Henze, D. K.: A 15-year record of $\mathrm{CO}$ emissions constrained by MOPITT CO observations, Atmospheric Chemistry And Physics, 17, 4565-4583, 10.5194/acp-17-4565-2017, 2017.

Jin, J., Lin, H. X., Heemink, A., and Segers, A.: Spatially varying parameter estimation for dust emissions using reduced-tangent-linearization 4DVar, Atmospheric Environment, 187, 358-373, 10.1016/j.atmosenv.2018.05.060, 2018.

Kang, J.-S., Kalnay, E., Miyoshi, T., Liu, J., and Fung, I.: Estimation of surface carbon fluxes with an advanced data assimilation methodology, 117, 10.1029/2012JD018259, 2012.

Kleist, D. T., Parrish, D. F., Derber, J. C., Treadon, R., Wu, W.-S., and Lord, S.: Introduction of the GSI into the NCEP Global Data Assimilation System, Weather and Forecasting, 24, 1691-1705, 10.1175/2009waf2222201.1, 2009.

Kong, L., Tang, X., Zhu, J., Wang, Z., Pan, Y., Wu, H., Wu, L., Wu, Q., He, Y., Tian, S., Xie, Y., Liu, Z., Sui, W., Han, L., and Carmichael, G.: Improved Inversion of Monthly Ammonia Emissions in China Based on the Chinese Ammonia Monitoring Network and Ensemble Kalman Filter, Environmental Science \& Technology, 53, 12529-12538, 10.1021/acsest.9b02701, 2019a.

Kong, L., Tang, X., Zhu, J., Wang, Z., Fu, J. S., Wang, X., Itahashi, S., Yamaji, K., Nagashima, T., 
Lee, H. J., Kim, C. H., Lin, C. Y., Chen, L., Zhang, M., Tao, Z., Li, J., Kajino, M., Liao, H., Sudo, K., Wang, Y., Pan, Y., Tang, G., Li, M., Wu, Q., Ge, B., and Carmichael, G. R.: Evaluation and uncertainty investigation of the $\mathrm{NO} 2, \mathrm{CO}$ and $\mathrm{NH} 3$ modeling over China under the framework of MICS-Asia III, Atmos. Chem. Phys. Discuss., 2019, 1-33, 10.5194/acp-2018-1158, $2019 \mathrm{~b}$.

Kurokawa, J.-i., Yumimoto, K., Uno, I., and Ohara, T.: Adjoint inverse modeling of NOx emissions over eastern China using satellite observations of NO2 vertical column densities, Atmospheric Environment, 43, 1878-1887, 10.1016/j.atmosenv.2008.12.030, 2009.

Li, M., Zhang, Q., Kurokawa, J.-i., Woo, J.-H., He, K., Lu, Z., Ohara, T., Song, Y., Streets, D. G., Carmichael, G. R., Cheng, Y., Hong, C., Huo, H., Jiang, X., Kang, S., Liu, F., Su, H., and Zheng, B.: MIX: a mosaic Asian anthropogenic emission inventory under the international collaboration framework of the MICS-Asia and HTAP, Atmospheric Chemistry and Physics, 17, 935-963, 10.5194/acp-17-935-2017, 2017.

Liu, Z., Liu, Q., Lin, H.-C., Schwartz, C. S., Lee, Y.-H., and Wang, T.: Three-dimensional variational assimilation of MODIS aerosol optical depth: Implementation and application to a dust storm over East Asia, Journal of Geophysical Research: Atmospheres, 116, n/a-n/a, 10.1029/2011jd016159, 2011.

Ma, C., Wang, T., Mizzi, A. P., Anderson, J. L., Zhuang, B., Xie, M., and Wu, R.: Multiconstituent Data Assimilation With WRF-Chem/DART: Potential for Adjusting Anthropogenic Emissions and Improving Air Quality Forecasts Over Eastern China, 124, 7393-7412, 10.1029/2019jd030421, 2019.

Meirink, J. F., Eskes, H. J., and Goede, A. P. H.: Sensitivity analysis of methane emissions derived from SCIAMACHY observations through inverse modelling, Atmospheric Chemistry and Physics, 6, 1275-1292, 10.5194/acp-6-1275-2006, 2006.

Miyazaki, K. and Eskes, H.: Constraints on surface NOx emissions by assimilating satellite observations of multiple species, Geophysical Research Letters, 40, 4745-4750, 10.1002/grl.50894, 2013.

Miyazaki, K., Eskes, H. J., and Sudo, K.: Global NOx emission estimates derived from an assimilation of OMI tropospheric NO2 columns, Atmospheric Chemistry and Physics, 12, 22632288, 10.5194/acp-12-2263-2012, 2012a.

Miyazaki, K., Eskes, H. J., Sudo, K., Takigawa, M., van Weele, M., and Boersma, K. F.: Simultaneous assimilation of satellite NO2, O-3, CO, and $\mathrm{HNO} 3$ data for the analysis of tropospheric chemical composition and emissions, Atmospheric Chemistry and Physics, 12, 9545-9579, 10.5194/acp-12-9545-2012, 2012 b.

Parrish, D. F. and Derber, J. C.: THE NATIONAL-METEOROLOGICAL-CENTERS SPECTRAL STATISTICAL-INTERPOLATION ANALYSIS SYSTEM, Monthly Weather Review, 120, 1747-1763, 10.1175/1520-0493(1992)120<1747:tnmcss >2.0.co;2, 1992.

Peng, Z., Liu, Z., Chen, D., and Ban, J.: Improving PM\&lt;sub\&gt;2. 5\&lt;/sub\&gt; forecast over China by the joint adjustment of initial conditions and source emissions with an ensemble Kalman filter, Atmospheric Chemistry and Physics, 17, 4837-4855, 10.5194/acp-17-4837-2017, 2017.

Peng, Z., Lei, L., Liu, Z., Su, J., Ding, A., Ban, J., Chen, D., Kou, X., and Chu, K.: The impact of multi-species surface chemical observation assimilation on air quality forecasts in China, Atmospheric Chemistry and Physics, 18, 10.5194/acp-18-17387-2018, 2018. 
Peters, W., Jacobson, A. R., Sweeney, C., Andrews, A. E., Conway, T. J., Masarie, K., Miller, J. B., Bruhwiler, L. M. P., Petron, G., Hirsch, A. I., Worthy, D. E. J., van der Werf, G. R., Randerson, J. T., Wennberg, P. O., Krol, M. C., and Tans, P. P.: An atmospheric perspective on North American carbon dioxide exchange: CarbonTracker, Proceedings of the National Academy of Sciences of the United States of America, 104, 18925-18930, 10.1073/pnas.0708986104, 2007.

Peylin, P., Rayner, P. J., Bousquet, P., Carouge, C., Hourdin, F., Heinrich, P., Ciais, P., and contributors, A.: Daily $\mathrm{CO} 2$ flux estimates over Europe from continuous atmospheric measurements: 1, inverse methodology, Atmospheric Chemistry and Physics, 5, 3173-3186, 10.5194/acp-5-3173-2005, 2005.

Purser, R. J., Wu, W. S., Parrish, D. F., and Roberts, N. M.: Numerical aspects of the application of recursive filters to variational statistical analysis. Part I: Spatially homogeneous and isotropic Gaussian covariances, Monthly Weather Review, 131, 1524-1535, 10.1175//15200493(2003)131<1524:naotao>2.0.co;2, 2003.

Rabier, F., McNally, A., Andersson, E., Courtier, P., Unden, P., Eyre, J., Hollingsworth, A., and Bouttier, F.: The ECMWF implementation of three-dimensional variational assimilation (3D-Var). II: Structure functions, Quarterly Journal Of the Royal Meteorological Society, 124, 1809-1829, 10.1256/smsqj.55002, 1998.

Sarwar, G., Simon, H., Bhave, P., and Yarwood, G.: Examining the impact of heterogeneous nitryl chloride production on air quality across the United States, Atmospheric Chemistry and Physics, 12, 6455-6473, 10.5194/acp-12-6455-2012, 2012.

Schwartz, C. S., Liu, Z., Lin, H.-C., and Cetola, J. D.: Assimilating aerosol observations with a "hybrid" variational-ensemble data assimilation system, Journal Of Geophysical ResearchAtmospheres, 119, 4043-4069, 10.1002/2013jd020937, 2014.

Sekiyama, T. T., Tanaka, T. Y., Shimizu, A., and Miyoshi, T.: Data assimilation of CALIPSO aerosol observations, Atmospheric Chemistry and Physics, 10, 39-49, 10.5194/acp-10-39-2010, 2010.

Shen, Y., Jiang, F., Feng, S., Zheng, Y., Cai, Z., and Lyu, X.: Impact of weather and emission changes on NO2 concentrations in China during 2014-2019, Environmental Pollution, 269, 116163, 10.1016/j.envpol.2020.116163, 2021.

Shi, X. and Brasseur, G. P.: The Response in Air Quality to the Reduction of Chinese Economic Activities During the COVID-19 Outbreak, 47, e2020GL088070, 10.1029/2020g1088070, 2020.

Stavrakou, T., Müller, J.-F., Boersma, K. F., De Smedt, I., and van der A, R. J.: Assessing the distribution and growth rates of NOx emission sources by inverting a 10-year record of NO2 satellite columns, 35, 10.1029/2008g1033521, 2008.

Sun, A. Y., Morris, A., and Mohanty, S.: Comparison of deterministic ensemble Kalman filters for assimilating hydrogeological data, Advances in Water Resources, 32, 280-292, 10.1016/j.advwatres.2008.11.006, 2009.

Takagi, H., Saeki, T., Oda, T., Saito, M., Valsala, V., Belikov, D., Saito, R., Yoshida, Y., Morino, I., Uchino, O., Andres, R. J., Yokota, T., and Maksyutov, S.: On the Benefit of GOSAT Observations to the Estimation of Regional $\mathrm{CO}<\mathrm{sub}>2</$ sub $>$ Fluxes, SOLA, 7, 161-164, 10.2151/sola.2011041,2011

Tang, X., Zhu, J., Wang, Z. F., and Gbaguidi, A.: Improvement of ozone forecast over Beijing based on ensemble Kalman filter with simultaneous adjustment of initial conditions and emissions, 
Atmospheric Chemistry And Physics, 11, 12901-12916, 10.5194/acp-11-12901-2011, 2011.

Tang, X., Zhu, J., Wang, Z. F., Wang, M., Gbaguidi, A., Li, J., Shao, M., Tang, G. Q., and Ji, D. S.: Inversion of $\mathrm{CO}$ emissions over Beijing and its surrounding areas with ensemble Kalman filter, Atmospheric Environment, 81, 676-686, 10.1016/j.atmosenv.2013.08.051, 2013.

Wang, C., Lei, L., Tan, Z.-M., and Chu, K.: Adaptive Localization for Tropical Cyclones With Satellite Radiances in an Ensemble Kalman Filter, Frontiers in Earth Science, 8, 10.3389/feart.2020.00039, 2020.

Whitaker, J. S. and Hamill, T. M.: Ensemble data assimilation without perturbed observations, Monthly Weather Review, 130, 1913-1924, 10.1175/15200493(2002)130<1913:Edawpo>2.0.Co;2, 2002.

Wu, H., Tang, X., Wang, Z., Wu, L., Li, J., Wang, W., Yang, W., and Zhu, J.: High-spatiotemporalresolution inverse estimation of $\mathrm{CO}$ and $\mathrm{NOx}$ emission reductions during emission control periods with a modified ensemble Kalman filter, Atmospheric Environment, 236, 10.1016/j.atmosenv.2020.117631, 2020.

Wu, W. S., Purser, R. J., and Parrish, D. F.: Three-dimensional variational analysis with spatially inhomogeneous covariances, Monthly Weather Review, 130, 2905-2916, 10.1175/15200493(2002)130<2905:tdvaws>2.0.co;2, 2002.

Zhang, F., Weng, Y., Sippel, J. A., Meng, Z., and Bishop, C. H.: Cloud-Resolving Hurricane Initialization and Prediction through Assimilation of Doppler Radar Observations with an Ensemble Kalman Filter, Monthly Weather Review, 137, 2105-2125, 10.1175/2009mwr2645.1, 2009a.

Zhang, Q., Streets, D. G., Carmichael, G. R., He, K. B., Huo, H., Kannari, A., Klimont, Z., Park, I. S., Reddy, S., Fu, J. S., Chen, D., Duan, L., Lei, Y., Wang, L. T., and Yao, Z. L.: Asian emissions in 2006 for the NASA INTEX-B mission, Atmospheric Chemistry and Physics, 9, 5131-5153, 10.5194/acp-9-5131-2009, 2009b.

Zhang, S., Zheng, X., Chen, J. M., Chen, Z., Dan, B., Yi, X., Wang, L., and Wu, G.: A global carbon assimilation system using a modified ensemble Kalman filter, Geosci. Model Dev., 8, 805-816, 10.5194/gmd-8-805-2015, 2015.

Zhang, X., Liu, J., Han, H., Zhang, Y., Jiang, Z., Wang, H., Meng, L., Li, Y. C., and Liu, Y.: SatelliteObserved Variations and Trends in Carbon Monoxide over Asia and Their Sensitivities to Biomass Burning, Remote Sensing, 12, 10.3390/rs12050830, 2020.

Zheng, B., Tong, D., Li, M., Liu, F., Hong, C., Geng, G., Li, H., Li, X., Peng, L., Qi, J., Yan, L., Zhang, Y., Zhao, H., Zheng, Y., He, K., and Zhang, Q.: Trends in China's anthropogenic emissions since 2010 as the consequence of clean air actions, Atmospheric Chemistry And Physics, 18, 14095-14111, 10.5194/acp-18-14095-2018, 2018. 